\title{
Mitochondria and Calcium Homeostasis: Cisd2 as a Big Player in Cardiac Ageing
}

\author{
Chi-Hsiao Yeh ${ }^{1,2,3}$,, Yi-Ju Chou ${ }^{4}$, Cheng-Heng Kao ${ }^{5, *}$ and Ting-Fen Tsai ${ }^{4,6,7,8, *}$ \\ 1 Department of Thoracic and Cardiovascular Surgery, Chang Gung Memorial Hospital, Linko 333, Taiwan; \\ yehccl@cgmh.org.tw \\ 2 College of Medicine, Chang Gung University, Taoyuan 333, Taiwan \\ 3 Community Medicine Research Center, Chang Gung Memorial Hospital, Keelung Branch, \\ Keelung 204, Taiwan \\ 4 Institute of Molecular and Genomic Medicine, National Health Research Institutes, Zhunan 350, Taiwan; \\ yjchou0810@nhri.edu.tw \\ 5 Center of General Education, Chang Gung University, Taoyuan 333, Taiwan \\ 6 Department of Life Sciences and Institute of Genome Sciences, National Yang-Ming University, \\ Taipei 112, Taiwan \\ 7 Institute of Biotechnology and Pharmaceutical Research, National Health Research Institutes, \\ Zhunan 350, Taiwan \\ 8 Aging and Health Research Center, National Yang-Ming University, Taipei 112, Taiwan \\ * Correspondence: cheng50@mail.cgu.edu.tw (C.-H.K.); tftsai@ym.edu.tw (T.-F.T.); \\ Tel.: +886-3-211-8800 (ext. 5149) (C.-H.K.); +886-2-2826-7293 (T.-F.T.); \\ Fax: +886-3-211-8700 (C.-H.K.); +886-2-2828-0872 (T.-F.T.)
}

Received: 7 November 2020; Accepted: 1 December 2020; Published: 3 December 2020 updates

\begin{abstract}
The ageing of human populations has become a problem throughout the world. In this context, increasing the healthy lifespan of individuals has become an important target for medical research and governments. Cardiac disease remains the leading cause of morbidity and mortality in ageing populations and results in significant increases in healthcare costs. Although clinical and basic research have revealed many novel insights into the pathways that drive heart failure, the molecular mechanisms underlying cardiac ageing and age-related cardiac dysfunction are still not fully understood. In this review we summarize the most updated publications and discuss the central components that drive cardiac ageing. The following characters of mitochondria-related dysfunction have been identified during cardiac ageing: (a) disruption of the integrity of mitochondria-associated membrane (MAM) contact sites; (b) dysregulation of energy metabolism and dynamic flexibility; (c) dyshomeostasis of $\mathrm{Ca}^{2+}$ control; (d) disturbance to mitochondria-lysosomal crosstalk. Furthermore, Cisd2, a pro-longevity gene, is known to be mainly located in the endoplasmic reticulum (ER), mitochondria, and MAM. The expression level of Cisd2 decreases during cardiac ageing. Remarkably, a high level of Cisd2 delays cardiac ageing and ameliorates age-related cardiac dysfunction; this occurs by maintaining correct regulation of energy metabolism and allowing dynamic control of metabolic flexibility. Together, our previous studies and new evidence provided here highlight Cisd2 as a novel target for developing therapies to promote healthy ageing
\end{abstract}

Keywords: cardiac ageing; Cisd2; mitochondria-associated membranes (MAMs); mitochondria; calcium homeostasis; energy flexibility 


\section{Introduction}

Despite the fact that the clinical management of cardiac diseases has improved over the past decades, cardiac disease remains the leading cause of mortality in an ageing population [1]. In particular, as the number of older individuals in populations has increased in many countries, a steep increase in age-related heart failure has begun to represent one of the greatest challenges confronting global health care [2]. In the United States of America, the estimated number of adults that are 20 years of age or older and have suffered from heart failure increased from 5.7 million between 2009 and 2012 to 6.2 million between 2013 and 2016 [1]; this suggests that there is similar higher prevalence all over the world [3]. The limited endogenous capacity of a heart to undergo repair/regeneration results in an accumulating burden of prior insults, which when combined with the structural and functional changes that occur during cardiac ageing, results in diminished cardiac reserves and an elevated risk of heart failure in older populations [4]. The grave prognosis for aged patients who have suffered heart failure is the result of a number of unknown molecular mechanisms that underlie the pathophysiology of cardiac ageing. However, accumulating evidence has shown that mitochondria play a central role in cardiac ageing and age-related cardiac diseases. Mitochondrial dysfunction brings about dysregulated $\mathrm{Ca}^{2+}$ homeostasis [5,6], impaired mitophagy [7,8], and metabolic inflexibility [9-11]. Healthy mitochondria are essential for cardiomyocytes to maintain a normal functionality in the heart.

Mitochondrial dysfunction is one of the hallmarks of ageing [12]. To meet the high-energy requirement of the heart, mitochondria occupy about $40 \%$ of the volume of cardiomyocytes [13]. Ageing affects the functioning of both mitochondria and the endoplasmic reticulum (ER), as well as having an impact on their contact sites in the cardiomyocytes, namely the mitochondria-associated membranes (MAMs). In the past decade, the markedly better understanding of the structures, tethers, and functions of MAMs has revealed the important roles that these structures play in cell physiology and ageing [14]. Four major functions of the membrane contact sites at MAMs have been identified, namely signaling, the regulation of organelle membrane dynamics, lipid transport, and metabolic channeling [14-16]. In an aged heart, age-related mitochondrial alterations include reduced mitochondrial $\mathrm{Ca}^{2+}$ uptake and diminished buffering capacity against reactive oxygen species (ROS); these result in impaired metabolism, which in turn bring about an increased sensitivity of the heart to stress, as well as compromising cardiac functioning. Therefore, a deeper understanding of mitochondrial and MAM functioning during cardiac ageing is pivotal to ultimately develop novel therapeutic strategies to reduce the burden of ageing.

CISD2 is an evolutionally conserved protein that is mainly located in the mitochondria, ER, and MAMs. The expression level of Cisd2 decreases during natural ageing in many tissues and organs, including the heart, skeletal muscles, liver, brain, and skin. Previously our studies have revealed that Cisd 2 knockout results in a premature aging phenotype with a shorten lifespan. Furthermore, Cisd2 deficiency leads to mitochondrial dysfunction, a disruption of cytosolic $\mathrm{Ca}^{2+}$ homeostasis, elevated ROS production, and dysregulated autophagy [17-23]. Conversely, a persistently high level of Cisd2, which can be achieved by transgenic overexpression, is able to reverse age-related cardiac dysfunction [19], Alzheimer's-related neuronal loss [23], nonalcoholic fatty liver disease [18], and sarcopenia [22]. It does the above by maintaining $\mathrm{Ca}^{2+}$ homeostasis, reducing ROS production, and improving metabolic flexibility. Recent genetic evidence highlights Cisd 2 as a promising new target for developing novel therapeutics that are aimed at attenuating cardiac ageing and providing a new avenue to geroprotection. 


\section{Defective Mitochondria-Lysosomal Crosstalk during Cardiac Ageing}

Cardiovascular disease is the leading cause of mortality among older adults [24]. At the structural level, age-related mitochondrial damage, which includes enlarged organelles, matrix derangement, and loss of cristae of mitochondrial inner membrane, is often found in aged hearts. At the functional level, age-related functional impairment, which includes decreased ATP production, increased ROS generation, and defective quality control, is also evident in aged hearts. All these defects contribute to pathogenesis during age-related heart failure [25]. In addition, during cardiac ageing, defective renewal mechanisms for various cellular constituents preclude the clearance of damaged biomolecules and senescent organelles. For example, accumulation of lipofuscin and degenerated mitochondria is evident in aged cardiac muscles. It should be noted that lipofuscin is considered to be one of the age-associated pigments and is found in skin, neurons, and cardiomyocytes $[26,27]$. These pigment granules are mainly composed of lipid material and highly oxidized proteins that cannot be digested by the ubiquitin-proteasome system and thus accumulate, primarily in lysosomes. The imbalanced lipid metabolism associated with mitochondria, the compromised enzymatic activity present in the lysosomes, and the presence of impaired autophagy pathways, together with inefficient cellular proteostasis, all seem to contribute to the formation of lipofuscin. Accordingly, the accumulation of nondegraded molecules in the lysosomes, including the deposition of lipofuscin, can be used to indicate the presence of age-related damage to both the mitochondria and lysosomes. These findings suggest that defective mitochondria-lysosomal crosstalk is present during cardiac ageing.

The most clinical relevant disorder related to lipofuscin accumulation is neuronal ceroid lipofuscinosis, which involves the accumulation of autofluorescent materials in cardiomyocytes [28,29]. Patients with neuronal ceroid lipofuscinosis display various clinical manifestations, including ventricular hypertrophy, sinus node dysfunction, and arrhythmia [29]; interestingly, these phenotypes are very similar to those associated with the age-related cardiac phenotype. Furthermore, a previous human study using cardiac samples from autopsy patients has revealed that the accumulation of myocardial lipofuscin directly reflects the chronological age of the heart rather than human cardiac pathology [27].

Intriguingly, our studies have shown that Cisd2 can delay cardiac ageing and this is associated with reduced lipofuscin accumulation and preserved myocardial ultrastructure. During the cardiac aging of WT mice, there is a significant increase in lipofuscin accumulation in myocardial tissues. Intriguingly, a high level of Cisd2 reduces lipofuscin accumulation in Cisd2TG mice, which form our long-lived mouse model. Conversely, Cisd2 deficiency significantly elevates lipofuscin accumulation in Cisd2KO mice, which form an accelerated aging mouse model (Figure 1A,B). Moreover, transmission electron microscopy (TEM) analysis has revealed that a high level of Cisd2 expression is able to diminish the accumulation of lipofuscin in cardiomyocytes, to preserve the structural integrity of myofibrils while at the same time ameliorating age-related damage to the ER and mitochondria (Figure 1C,D). 
A
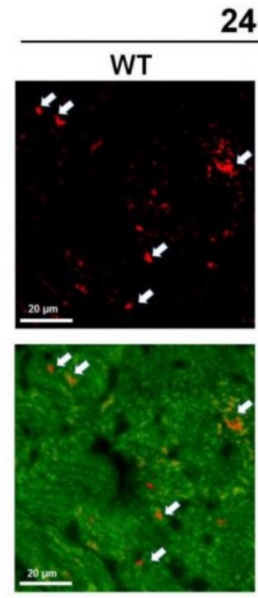

24-mo WT
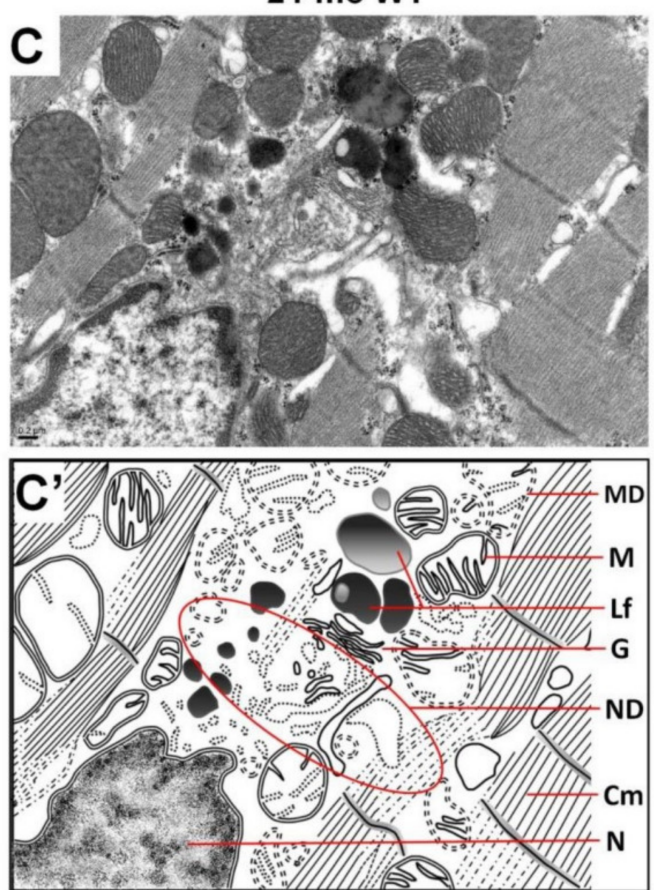

B

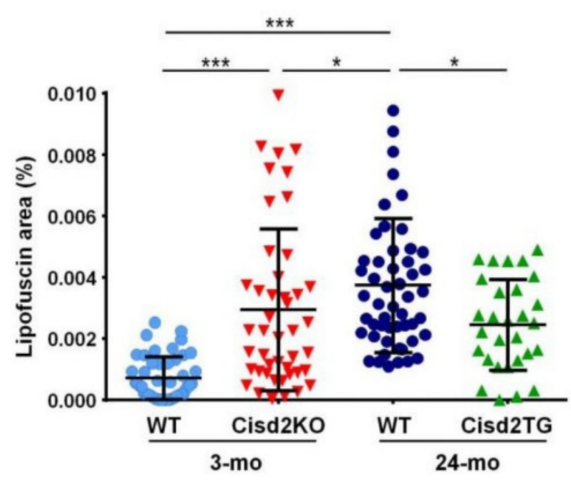

24-mo Cisd2TG
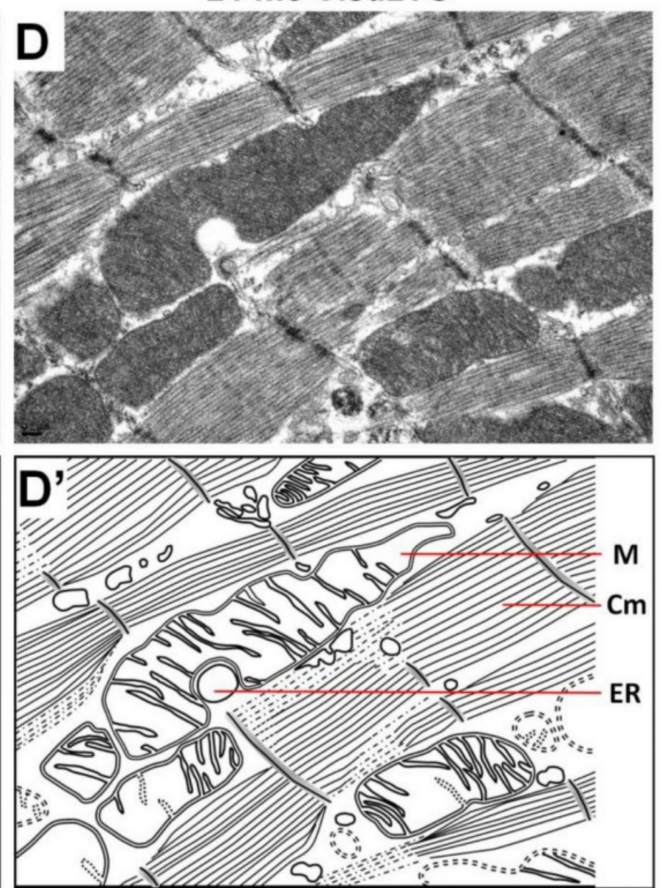

Figure 1. Cisd2 delays cardiac ageing as revealed by reduced lipofuscin accumulation and preserved myocardial ultrastructure. (A) Lipofuscin deposits can be clearly identified in cardiac tissues by autofluorescence detected with 330-380 nm excitation light and $420 \mathrm{~nm}$ barrier filter of a confocal fluorescence microscope. The red color indicates lipofuscin and green color indicates myocardia. (B) There is a significant increase of lipofuscin accumulation during cardiac ageing of WT mice. Intriguingly, a high level of Cisd2 reduces lipofuscin accumulation in Cisd2TG mice, while Cisd2 deficiency significantly elevates lipofuscin accumulation in Cisd2KO mice. The areas of lipofuscin accumulation and the myocardia are measured using Fiji/ImageJ 1.52e (National Institutes of Health, Bethesda, MD, USA). Ten fields per subject are observed at $20 \times$ objective magnification, and the lipofuscin accumulation (lipofuscin deposit area/myocardial area) was calculated. ${ }^{*} p<0.05,{ }^{* *} p<0.01$, *** $p<0.001$. (C,D) Transmission electron microscopy (TEM) analysis for the left ventricle of heart. In 24-mo WT mice (C), age-associated mitochondria degeneration, lipofuscin accumulation, and necrotic debris of degenerative myofibril and organelles are detectable and easily identified. (D) In 24-mo Cisd2TG mice, relatively normal ultrastructures, namely intact mitochondria, ER, and cardiac myofibrils, are found. $\left(\mathbf{C}^{\prime}\right)\left(\mathbf{D}^{\prime}\right)$ Schematic presentation for ultrastructure of left ventricle shown in (C) and (D), respectively. MD: mitochondrial degeneration, Lf: lipofuscin, ND: necrotic debris of degenerative myofibril and organelles, G: Golgi apparatus, M: mitochondria, Cm: cardiac myofibril, ER: endoplasmic reticulum, N: nucleus. 


\section{Cisd2 Deficiency Causes Dysregulation of Intracellular $\mathrm{Ca}^{2+}$ Homeostasis}

\subsection{Mitochondria and Cellular $\mathrm{Ca}^{2+}$ Homeostasis}

Calcium signaling plays a crucial role in many molecular processes and a range of cellular functions. Accumulating evidence indicates that $\mathrm{Ca}^{2+}$ strictly controls cellular senescence [6]. An elevation of intracellular $\mathrm{Ca}^{2+}$ levels has been observed in response to different types of stresses. Mitochondria, equipped with $\mathrm{Ca}^{2+}$ uniporters and a negative membrane potential (about $-180 \mathrm{mV}$ ), are able to function as a potent $\mathrm{Ca}^{2+}$ buffering organelle when there is an elevation in intracellular $\mathrm{Ca}^{2+}$ concentration $\left(\left[\mathrm{Ca}^{2+}\right]_{\mathrm{i}}\right)[30]$. Furthermore, mitochondrial $\mathrm{Ca}^{2+}$ signaling increases when an advanced age is reached [31]. The ER and mitochondria are the two major organelles that govern the intracellular storage, sequestration, and release of $\left[\mathrm{Ca}^{2+}\right]_{i}[32,33]$. An elevation in $\left[\mathrm{Ca}^{2+}\right]_{i}$ is usually attributable to a $\mathrm{Ca}^{2+}$ influx from the extracellular milieu via plasma membrane $\mathrm{Ca}^{2+}$ channels or from intracellular stores of $\mathrm{Ca}^{2+}$ present in the ER [6]. Any release of $\mathrm{Ca}^{2+}$ from ER elevates the cytosolic $\mathrm{Ca}^{2+}$ and this occurs in combination with ever larger cycles of mitochondrial $\mathrm{Ca}^{2+}$ uptake [34]. These increases in mitochondrial $\mathrm{Ca}^{2+}$ concentration leads to a drop in mitochondrial membrane potential, which in turn enhances the production of ROS. As a result, oxidative stress increases further, triggering senescence [6], as well as organ dysfunction, during the aging process [31]. Mitochondrial $\mathrm{Ca}^{2+}$ uniporter (MCU) and $\mathrm{H}^{+} / \mathrm{Ca}^{2+}$ exchanger LETM1 are the two main transporters responsible for mitochondrial $\mathrm{Ca}^{2+}$ uptake [35,36]; on the other hand, $\mathrm{NCX}\left(\mathrm{Na}^{+} / \mathrm{Ca}^{2+}\right.$ exchanger) and $\mathrm{H}^{+} / \mathrm{Ca}^{2+}$ exchanger are the two transporters that export $\mathrm{Ca}^{2+}$ back to cytoplasm [30,37].

\subsection{ER-Mitochondrial $\mathrm{Ca}^{2+}$ Dysregulation and Cardiac Ageing}

The ER, which consists of a spatially extended membranous network, is often positioned in close proximity to other cellular organelles and these areas form membrane contact sites [38]. The sites of physical interaction and communication between the ER and mitochondria, namely the mitochondria-associated ER membranes (MAMs), represents a platform that is fundamentally important to the modulation of $\mathrm{Ca}^{2+}$ homeostasis, autophagy, apoptosis, lipid metabolism, metabolic diseases, and tumor growth; these events are mediated via the exchange of lipids and $\mathrm{Ca}^{2+}$ ions $[5,16,39-42]$. The conserved structures of MAMs found across eukaryotic phyla are key determinants of cell survival and their functionality, which involves the bidirectional trafficking of factors between the two organelles [43,44]. This means that MAMs are dynamic structures that are sensitive to the physiological conditions within cells [16].

Four major functions have been identified for MAMs. These are (a) control of $\mathrm{Ca}^{2+}$ signaling, (b) regulation of mitochondrial division, (c) accommodation of lipid biosynthesis, and (d) coordination of the dynamic interactions between mitochondria and the ER [44]. Importantly, MAMs provide an efficient way for $\mathrm{Ca}^{2+}$ traffic to take place between the ER and mitochondria and this allows the creation of a higher $\mathrm{Ca}^{2+}$ concentration close to the MAMs compared to the surrounding cytoplasm. The $\mathrm{Ca}^{2+}$ released from the ER via the MAMs to the mitochondria means that this high local concentration of $\mathrm{Ca}^{2+}$ is able to activate various $\mathrm{Ca}^{2+}$-dependent processes. These include the tricarboxylic acid (TCA) cycle, oxidative phosphorylation, the regulation of ROS signaling, cell death, and the stimulation of mitochondrial division [14,44-46]. A functional protein complex is essential for the tethering of ER-mitochondria and for maintaining the MAM structure; this complex is formed via inositol 1,4,5-trisphosphate receptors (IP3Rs) at ER, voltage dependent anion-selective channel (VDAC) protein in the mitochondrion, and the chaperone $75 \mathrm{kDa}$ glucose regulated protein (GRP75) [14]. In cardiac and skeletal muscle, the $\mathrm{Ca}^{2+}$ channel in the ER, namely the ryanodine receptor (RYR), also allows $\mathrm{Ca}^{2+}$ traffic from ER to mitochondria close to the MAMs [47]. Many other tether complexes of MAMs had also been reported [38]. Interestingly, when the hearts of Mfn2KO mice are examined, the contact lengths of MAMs are reduced by $30 \%$; this is accompanied by an increased level of ROS, and reduced cardiac contractility [48]. Using the norepinephrine-induced cardiac hypertrophic model, it has been shown that the distance between the ER and mitochondria is increased and that this is accompanied by 
impaired $\mathrm{Ca}^{2+}$ trafficking between the two organelles [49]. Indeed, alterations in the contact length and gap distance of MAMs had been reported to dysregulate $\mathrm{Ca}^{2+}$ signaling and affect cardiac metabolism, thereby accelerating cardiac ageing and promoting the development of cardiac hypertrophy, as well as heart failure [50].

\subsection{Cisd2 Maintains $\mathrm{Ca}^{2+}$ Homeostasis}

Cisd2 is mainly located in the mitochondrial outer membrane and the ER. In particular, Cisd2 is highly enriched in the MAMs. Previous studies by our group and other researchers have revealed that the intracellular localization and binding partners of Cisd2 vary with the cell type and/or with the experimental conditions [51]. This scenario helps to explain why different proteins have been found to interact with Cisd 2 under a variety of circumstances $[18,19,21-23,52,53]$. For example, in the skeletal muscle, Cisd2 appears to associate with $\mathrm{Bcl}-2 / \mathrm{Bcl}-\mathrm{XL}$ and IP3R when participating in the regulation of the ER Ca ${ }^{2+}$ store. Loss of Cisd2 in myocytes results in a dysregulation of $\mathrm{Ca}^{2+}$ homeostasis that is accompanied by augmented autophagy and the presence of degenerated ER [52,53]. On the other hand, in the liver, Cisd2 interacts directly with Serca2b, which is a $\mathrm{Ca}^{2+}$-pump that transports $\mathrm{Ca}^{2+}$ from the cytosol into the ER. Furthermore, investigations have revealed that Cisd 2 directly binds to Serca2a in cardiomyocytes. In both cases, this allows there to be control of $\mathrm{Ca}^{2+}$ pump activity by these two proteins via modulation of their oxidative modification. This in turn regulates $\mathrm{ER} \mathrm{Ca}^{2+}$ uptake by Serca2a and Serca2b, which then sustains $\mathrm{Ca}^{2+}$ homeostasis in the heart and liver, respectively $[18,19]$. Finally, in adipocytes, our research has revealed that Cisd2 interacts directly with Gimap5 (GTPase of immune-associated protein 5) on the mitochondrial and ER membranes in order to modulate the $\mathrm{Ca}^{2+}$ buffering capacity of mitochondria, thereby maintaining the intracellular $\mathrm{Ca}^{2+}$ homeostasis of adipocytes. Loss of Cisd2 increases the cytosolic level of $\mathrm{Ca}^{2+}$, and induces $\mathrm{Ca}^{2+}$-calcineurin-dependent signaling that inhibits adipogenesis [21].

Mechanistically, one important question is how Cisd2 modulates intracellular $\mathrm{Ca}^{2+}$ homeostasis via its interaction with its partner proteins. Here we use Serca2 as an example to illustrate the potential molecular mechanism behind the regulation of $\mathrm{Ca}^{2+}$ via Serca2a in the cardiomyocytes and Serca2b in the hepatocytes $[18,19]$. Three possibilities may explain how the redox status of Serca2a and Serca2b is affected by Cisd2. First, the only defined functional domain of the Cisd2 protein is the protein's CDGSH domain, which binds a redox-active $2 \mathrm{Fe}-2 \mathrm{~S}$ cluster and is oriented toward the cytosol. It seems likely that Cisd2 directly interacts with Serca2 to help maintain Serca2b in a reduced state via the redox capacity of the CDGSH domain present on Cisd2. Second, Cisd2 may cover a part of Serca2 via protein-protein interaction, thus reducing the accessibility of certain tyrosines and cysteines present on Serca 2 to attack by enzymes; as a consequence, this may prevent Serca2 from undergoing irreversible oxidative modification (cysteine sulfonation and tyrosine nitration) during oxidative stress. Finally, the redox-active CDGSH domain of Cisd2 may contribute to the maintenance of the general redox status of the cell. This will act to reduce the overall oxidative stress in the cell and indirectly protect Serca2 activity from ROS-mediated and/or RNS-mediated protein oxidation that can bring about a reduction in the protein's $\mathrm{Ca}^{2+}$ pumping activity. These possibilities are not exclusive, but rather all may contribute to maintaining the redox homeostasis of the Serca2b protein [18].

\subsection{Cisd2 Protects the Interfibrillar and Subsarcolemmal Mitochondria from Age-Related Damage}

Mitochondria can be divided into three distinct populations based on their location and proximity to $\mathrm{Ca}^{2+}$ release sites [54]. These are, firstly, perinuclear mitochondria (PNMs), which are arranged in clusters and located adjacent to the nucleus; their function is presumably associated with transcription. Secondly, there are subsarcolemmal mitochondria (SSMs), which are also arranged in clusters, but are located just beneath the sarcolemma; their function is presumably associated with the functioning of ion channels and various signaling pathways. Thirdly, there are the interfibrillar mitochondria (IFMs), which are arranged in rows alongside the myofibrils and are located very close to the $\mathrm{Ca}^{2+}$ release sites 
of the SR; their function is presumably to generate ATP that then contributes to the contractile function of myofibrils, as well as to participate in the $\mathrm{Ca}^{2+}$ signaling within cardiomyocytes [55].

The IFMs are probably the most susceptible mitochondria to age-related damage. Previous studies have revealed that, during the ageing of cardiomyocytes, there is an increase in mitochondrial ROS and a decrease in antioxidant capacity that leads to an increased accumulation of oxidative damage with the DNA [56]; notably this is almost exclusively associated with the IFMs [57]. The abundance of IFMs and their physically close association with myofilaments suggests that IFMs provide the energy needed for cardiomyocyte contraction and thus have a higher respiratory capacity than SSMs [58]. Therefore, any loss of IFMs is likely to adversely affect muscle contractility by limiting the ATP production required by myosin ATPases. Moreover, the increased ROS level associated with aged IFMs is likely to exacerbate mitochondria-derived oxidant injury to the myofilaments; this in turn will lead to increased fibrosis and/or fiber disarrangement, thereby decreasing the contractile capacity of the heart [59]. Additionally, a previous study has shown that decreased mitophagy is accompanied by mitochondrial fragmentation in aging hearts [60]. Intriguingly, these ultrastructural alterations to the IFMs, namely the presence of fragmented mitochondria, the appearance of disarranged and degenerative myofibrils, and the presence of myofibril/organelle necrotic debris, seem to be absent in 24-mo old Cisd2TG mice, which is not the case in naturally aged 24-mo old WT mice (Figure 1C,D).

The function of SSMs is presumably related to ATP production that allows electrolyte and protein transport across the sarcolemma [58]. The exclusive localization of Connexin 43, which is the major component of gap junctions for cell-cell communication, within the SSMs further pinpoints their important role in electrical conductance within the heart [61]. In the naturally aged (24-mo old WT) and prematurely aged (3-mo old Cisd2KO) mice, the SSMs have largely disappeared with only a few degenerating SSMs remaining detectable. This seems to explain the presence of the age-related cardiac conductance abnormalities that occur during ageing (Figure 2A). Remarkably, in the long-lived mice (24-mo old Cisd2TG), a persistently higher level of Cisd2 is able to eliminate age-related damage to the SSMs in the cardiomyocytes; the amount and structural integrity of SSM in the 24-mo old Cisd2TG is similar to that of 3-mo old young WT mice (Figure 2A). This result is consistent with our previous study [19] wherein a higher level of Cisd2 was found to preserve functional mitochondria. This will, in turn, provide a stable MAM microenvironment that ensures efficient communication between the ER and mitochondria, thereby maintaining intracellular $\mathrm{Ca}^{2+}$ homeostasis in the cardiomyocytes. This means that any age-related functional decline of an aging heart, namely changes to mechanical contractility and electrical conductance, are attenuated by the presence of the Cisd2 protein.

\subsection{Cisd2 Maintains the MAMs during Cardiac Ageing}

Normal functioning of MAMs is associated with there being an appropriate width of the cleft between the mitochondrial outer membrane $(\mathrm{OMM})$ and the ER [62]. Certain structural arrangements within the space that separates the ER and mitochondria are able to support an optimal $\mathrm{Ca}^{2+}$ transfer via the $\mathrm{Ca}^{2+}$ transport channels [46]. Thus, there is an optimal distance of $\approx 30 \mathrm{~nm}$ between ER and mitochondria that allows effective $\mathrm{Ca}^{2+}$ transfer from ER, through the $\mathrm{Ca}^{2+}$ channel $\mathrm{IP}_{3} \mathrm{R}$ located in $\mathrm{ER}$, to the mitochondria, through the $\mathrm{Ca}^{2+}$ channel MCU located in mitochondria. This $\mathrm{Ca}^{2+}$ transfer contributes to the generation of physiologically relevant cytosolic $\mathrm{Ca}^{2+}$ oscillations [63]. In addition, a previous study has defined the role of this microenvironment as being the key compartment driving cytosolic $\mathrm{Ca}^{2+}$ oscillations. The microenvironment between the ER and mitochondria plays a critical role in $\mathrm{Ca}^{2+}$ dynamics by modulating the activity of IP3Rs and allowing the shuttling of $\mathrm{Ca}^{2+}$ between the ER and mitochondria [64]. A disruption of ER-mitochondria integrity and communication and a consequential dysregulation of $\mathrm{Ca}^{2+}$ homeostasis have been linked with pathogenesis, aberrant metabolism [38,42], neurodegenerative disease [38], a decreased lifespan [65], and ageing [15,41]. 

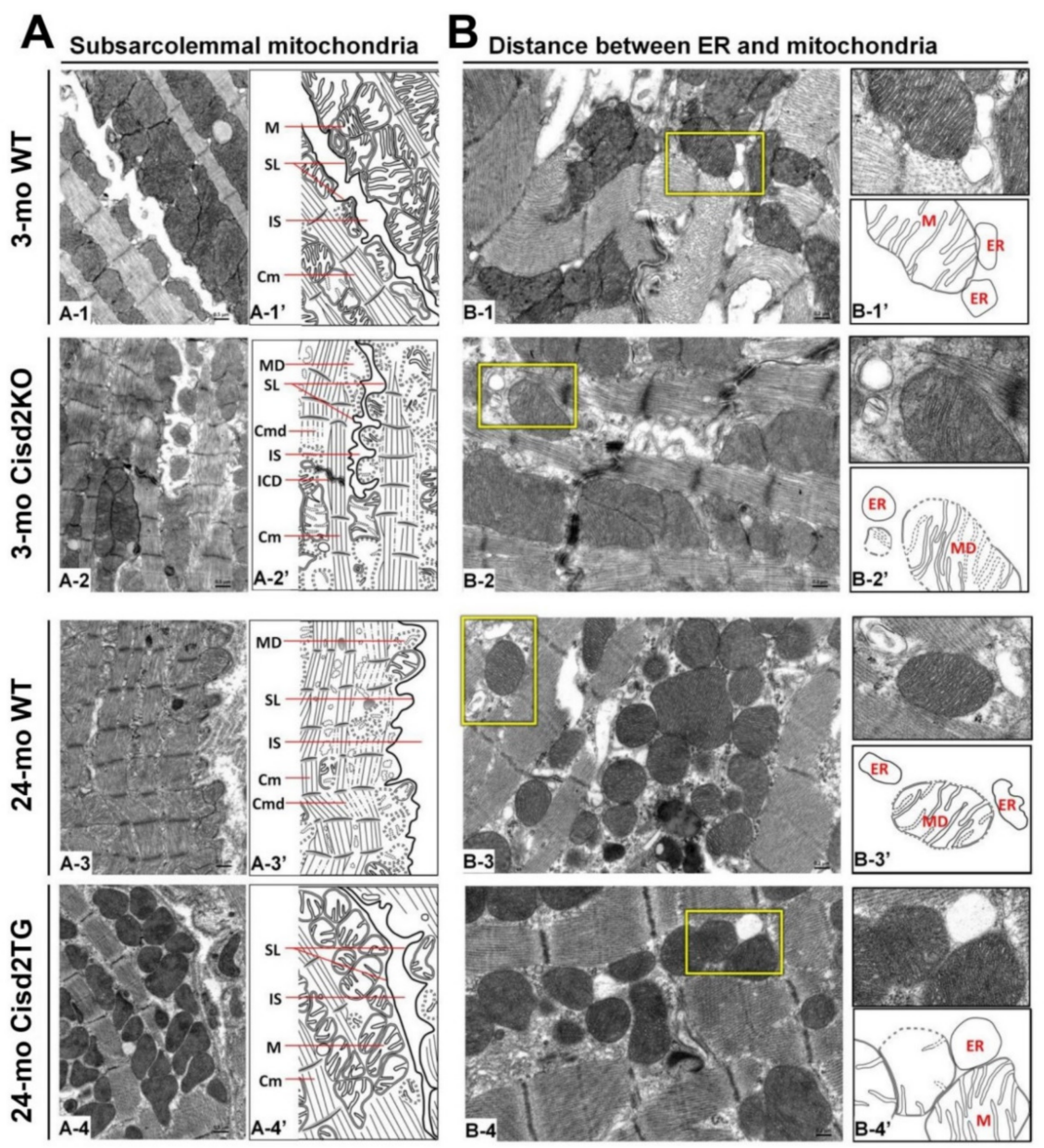

Figure 2. Cisd2 preserves the integrity of subsarcolemmal mitochondria and maintains the ultrastructure of mitochondria-associated ER membrane (MAM). (A) Cisd2 preserves the integrity of subsarcolemmal mitochondria and cardiac myofibrils of left ventricle. In 3-mo WT mice, there is an abundance of normal subsarcolemmal mitochondria and normal cardiac myofibrils (A-1 and A-1'). In 3-mo Cisd2KO mice (prematurely aged), notably, a low density of subsarcolemmal mitochondria, and degeneration of mitochondria and myofibrils are found (A-2 and A-2'). In 24-mo WT mice (naturally aged), similar ultrastructural damages are found as those observed in the 3-mo Cisd2KO mice (A-3 and A-3'). Remarkably, in 24-mo Cisd2TG mice, a high level of Cisd2 preserves the density and integrity of subsarcolemmal mitochondria as well as maintains the ultrastructure of cardiac myofibrils (A-4 and $\left.\mathrm{A}-4^{\prime}\right) .\left(\mathrm{A}-1^{\prime}\right)$ to $\left(\mathrm{A}-4^{\prime}\right)$ are schematic presentations for ultrastructure of left ventricle shown in (A-1) to (A-4). SL: sarcolemma, IS: intercellular space, M: mitochondria, Cm: cardiac myofibril, ICD: intercalated disc, MD: mitochondrial degeneration, Cmd: cardiac myofibril degeneration. (B) Cisd2 is essential to maintaining the integrity of MAM. In 3-mo WT mice, at MAM, mitochondria closely attach to ER (B-1 and B-1'). In 3-mo Cisd2KO mice, notably, a longer distance between mitochondria and ER is found; in addition, mitochondria degeneration is also found (B-2 and B-2'). In 24-mo WT mice, a longer distance between mitochondria and ER is found; this is similar to that observed in the 3-mo Cisd2KO mice (B-3 and B-3'). Intriguingly, in 24-mo Cisd2TG mice, a high level of Cisd2 maintains a relatively normal MAM, where the mitochondria closely attach to the ER (B-4 and B-4'). (B-1') to (B-4') are schematic presentations for the ultrastructure of left ventricle shown in (B-1) to (B-4). The inset shows a higher magnification to provide a better illustration for MAM. The inset shows a higher magnification of the selected area (yellow squares) of the middle panel to provide a better illustration for MAM.

If the cleft between OMM and ER is too narrow, this causes various abnormalities. For example, under ER stress, MAMs become closer to the mitochondria, with a $25 \%$ decrease in distance and a $60 \%$ increase in contact length between the two organelles [39]. This results in an enhanced transport of $\mathrm{Ca}^{2+}$ 
from the ER to the adjacent mitochondrial network, which stimulates oxidative metabolism and induces the apoptotic program [16,34]. Additionally, during long-term cultured neuron, which is a neuronal senescence model, an increased $\mathrm{Ca}^{2+}$ transport from the ER to mitochondria has been associated with an upregulation of the MCU [66]. Thus, it seems that increased $\mathrm{Ca}^{2+}$ transfer to mitochondria and an accumulation of $\mathrm{Ca}^{2+}$ within the mitochondria seems to serve as one of the mechanisms underlying the loss of mitochondrial membrane potential and the induction of cell senescence [67].

If the cleft between the OMM and ER is too wide, this also causes problems. A previous study has revealed that abnormally high cytosolic $\mathrm{Ca}^{2+}$ develops when the distance is greater than the optimum [63]. Remarkably, our studies have revealed that Cisd2 deficiency or a decreased expression of Cisd 2 to less than $50 \%$, namely haploinsufficient, disrupts $\mathrm{Ca}^{2+}$ homeostasis and causes elevated cytosolic $\mathrm{Ca}^{2+}$ levels. This Cisd2-mediated $\mathrm{Ca}^{2+}$ dysregulation is accompanied by abnormal dilation of the ER and a breakdown of the mitochondrial outer membrane [17-19] in many different tissues and organs, including brown adipose tissue [68], skeletal muscles [22,53], during neurodegenerative Alzheimer's disease [23], and during cardiac dysfunction [19].

In naturally aged WT mice at 24-mo old, in which the level of Cisd2 has decreased to less than $50 \%$ in the heart, and in prematurely aged Cisd2KO mice at 3-mo old, in which Cisd 2 expression is completely eliminated in the heart, the MAM gap distance is obviously increased (Figure 2B); this seems to provide an explanation for the differences in cardiac metabolism and $\mathrm{Ca}^{2+}$ signaling that occur with these two mouse models [19]. Intriguingly, in the long-lived Cisd2TG mice at 24-mo old, in which Cisd2 is 2-fold higher in the heart, the compactness and proximity of the ER and mitochondria appears to be well preserved (Figure 2B). This probably ensures that there is correct contact of the mitochondria with the MAM, which then allows normal $\mathrm{Ca}^{2+}$ trafficking between these two organelles to be maintained. The cardiac phenotypes of Cisd2KO mice and Cisd2TG mice are summarized in Table 1.

Table 1. Compare the cardiac phenotypes of WT, Cisd2KO and Cisd2TG mice.

\begin{tabular}{|c|c|c|c|c|}
\hline Age & & $\begin{array}{c}\text { Young Age } \\
\text { (3 Months Old) }\end{array}$ & $\begin{array}{r}\text { Old A } \\
(24-26 \text { Mon }\end{array}$ & $\begin{array}{l}\text { ge } \\
\text { ths Old) }\end{array}$ \\
\hline Genotype & WT & Cisd2KO & WT & Cisd2TG \\
\hline Genetic modification & - & Conventional Cisd2 KO & - & $\begin{array}{l}\text { Carrying } 4 \text { copies of } \\
\text { Cisd2 gene }\end{array}$ \\
\hline Cisd2 protein level & $100 \%$ & $0 \%$ & $50 \%$ & $100-130 \%$ \\
\hline $\begin{array}{c}\text { Cardiac mechanical } \\
\text { function (Ejection Fraction) }\end{array}$ & $\sim 85 \%$ & $\begin{array}{c}\sim 80 \% \\
(\sim 70 \% \text { at } 6 \text { months old })\end{array}$ & $\sim 60 \%$ & $\sim 75 \%$ \\
\hline Cardiac electrical function & Sinus rhythm & $\begin{array}{ll}\text { - } & \text { Frequent APCs }{ }^{1} \\
\text { - } & \text { Frequent VPCs }{ }^{6} \\
\text { - } & \text { Atrioventricular block } \\
\text { - } & \text { Prolonged Tpeak-Tend interval } \\
\text { - } & \text { Prolonged corrected QT interval }\end{array}$ & $\begin{array}{ll}\text { - } & \text { Frequent APCs }{ }^{1} \\
\text { - } & \text { Frequent VPCs }{ }^{6} \\
\text { - } & \text { Atrioventricular block } \\
\text { - } & \text { Prolonged } \\
& \text { Tpeak-Tend interval } \\
\text { - } & \text { Prolonged corrected } \\
& \text { QT interval }\end{array}$ & $\begin{array}{ll}\text { - } & \text { Rare APCs }{ }^{1} \\
\text { - } & \text { Rare VPCs }\end{array}$ \\
\hline Histopathology & Rare lipofuscin & $\begin{array}{l}\text { - Increased interstitial fibrosis } \\
\text { - } \quad \text { Increased lipofuscin }\end{array}$ & $\begin{array}{ll}\text { - Increased interstitial fibrosis } \\
\text { - Increased lipofuscin }\end{array}$ & $\begin{array}{ll}\text { - } & \text { Mild increased } \\
\text { interstitial fibrosis } \\
\text { - } & \text { Mild increased lipofuscin }\end{array}$ \\
\hline $\begin{array}{l}\text { Ultrastructure of } \\
\text { cardiomyocyte }\end{array}$ & Normal & $\begin{array}{ll}\text { - } & \text { Mitochondrial degeneration } \\
\text { - } & \mathrm{SR}^{5} \text { dilatation } \\
\text { - } & \text { Increased Gap between } \mathrm{MAM}^{3} \\
\text { - } & \text { Gap junction extension } \\
& \text { and fragmentation } \\
\text { - } & \text { Myofibril disorganization } \\
\text { - } & \text { Fascia adherens breakdown } \\
\text { - } & \text { Desmosome degeneration } \\
\end{array}$ & $\begin{array}{ll}\text { - } & \text { Mitochondrial degeneration } \\
\text { - } & \mathrm{SR}^{5} \text { dilatation } \\
\text { - } & \text { Increased Gap between } \\
& \mathrm{MAM}^{3} \\
\text { - } & \text { Myofibril disorganization } \\
\text { - } & \text { Disorganization of } \\
& \text { intercalated disc } \\
\text { - } & \text { Expanded intercellular space }\end{array}$ & $\begin{array}{l}\text { - Relatively normal or } \\
\text { mild damage }\end{array}$ \\
\hline Calcium homeostasis & Normal & $\begin{array}{ll}\text { - } & \text { Decreased Serca2a activity } \\
\text { - } & \text { Decreased }\left[\mathrm{Ca}^{2+}\right]_{\mathrm{Cyt}}{ }^{2} \\
\text { - } & \text { Decreased }\left[\mathrm{Ca}^{2+}\right]_{\mathrm{SR}}{ }^{5} \\
\text { - } & \text { Increased }\left[\mathrm{Ca}^{2+}\right]_{\text {Mito }}{ }^{4} \\
\end{array}$ & - Decreased Serca2a activity & $\begin{array}{l}\text { - Mild decrease of } \\
\text { Serca2a activity }\end{array}$ \\
\hline Mito ${ }^{4}$ function (OCR) & $100 \%$ & $61 \%$ & Not determined & Not determined \\
\hline $\begin{array}{l}\text { Oxidative stress } \\
\text { (fold increase) }\end{array}$ & 1.0 & 2.3 & 2.6 & 1.2 \\
\hline
\end{tabular}




\section{Metabolic Reprogramming during Cardiac Ageing}

\subsection{Metabolic Reprogramming during Ageing and Its Relationship with Age-Related Cardiac Dysfunction}

In the normal myocardium, the heart relies on cardiac mitochondria to generate $90-95 \%$ of the ATP it needs via mitochondrial oxidative phosphorylation (OXPHOS) and then uses this ATP to maintain the cardiac functioning [69-71]; only $5-10 \%$ of ATP needed is generated by anaerobic glycolysis in the cytosol [72]. The ATP generated from OXPHOS is classified as being $40-60 \%$ from fatty acid oxidation (FAO), $20-40 \%$ from carbohydrate metabolisms via pyruvate and lactate, and $8-10 \%$ from ketone body metabolism (of the last, $\beta$-hydroxybutyrate and acetoacetate account for $2.6 \% \pm 0.3 \%$ and $6.0 \% \pm 1.0 \%$, respectively) [9]. Under different conditions, the energy supply from fatty acids and carbohydrates can be dynamically adjusted, which has been named heart metabolic flexibility [59]. Cardiac mitochondria play an important role not only in biogenesis, but also in the metabolic balance between glycolysis and FAO. In addition, the "creatine kinase-phosphocreatine ( $\mathrm{PCr}$ ) energy shuttle" is pivotal to the energy transfer and storage of such large amount of a high-energy phosphate compound as ATP [73].

The ageing hearts usually shift their energy resources toward a greater reliance on glycolysis and ketone body oxidation and this is accompanied by a decrease in the contribution of mitochondrial OXPHOS. This can aggravate cardiac dysfunction and bring about a progression towards heart failure during ageing $[9,15]$. During ageing, FAO is decreased and glucose metabolism is enhanced, which leads to lipid accumulation and cell death in the ageing heart, accompanied by fibrosis. Additionally, previous studies have demonstrated that the ATP/PCr ratio is significantly reduced in a failing human myocardium. The efficiency of energy production and of high-energy phosphate metabolism also decline with age [10]. This decline in cardiac metabolic functioning and the associated reprogramming of the heart's energy metabolic pathways are probably good targets for the development of novel drugs that are able to delay cardiac ageing and treat age-related cardiac diseases.

\subsection{Understanding the Mechanisms behind the Metabolic Reprogramming of the Ageing Heart}

Defects affecting cardiac metabolic functions are mainly caused by (1) impaired FAO and increased lipid accumulation, (2) reduced glucose oxidation and increased pentose phosphate pathway (PPP), (3) inefficient ketone body metabolism, and (4) mitochondrial dysfunction and diminished OXPHOS. Together, these age-dependent dysregulations in energy metabolism and the loss of metabolic flexibility lead to reduced ATP production and result in an inadequate energy supply fueling cardiomyocytes. This then leads to cardiac dysfunction and the development of age-related cardiac diseases in an ageing heart.

\subsubsection{Reduced Glucose Oxidation and Increased PPP}

In the aging hearts, energy metabolism switches from the utilization of fatty acids toward using glucose as an energy source. The glycolytic rate is increased and this is likely brought about by the increase in activity of ATP-dependent 6-phosphofructokinase (PFK1), the rate-limiting enzyme of glycolosis [74]. However, the whole glycolytic pathway is impaired. As a result, the downstream TCA cycle and the mitochondrial ETC both have diminished activity due to an insufficient supply of electron carriers, namely NADH and $\mathrm{FADH}_{2}$, entering the ETC and generating ATP [74-81]. Therefore, although the amount of glucose utilization is increased, the absolute amount of ATP produced by glucose oxidation declines (Figure 3A). Previously Randle and colleagues have proposed a "glucose-fatty acid cycle" to describe fuel selection by various tissues. They demonstrated that the utilization of one nutrient, namely glucose or fatty acid, is able to inhibit the use of the other directly and without hormonal mediation [82]. This Randle cycle of glucose-fatty acid competition is thus a biochemical mechanism for controlling fuel selection. This seems to provide a possible explanation, at least in part, as to why the utilization of glucose is significantly elevated in the ageing heart when fatty acid metabolic pathways are impaired. 


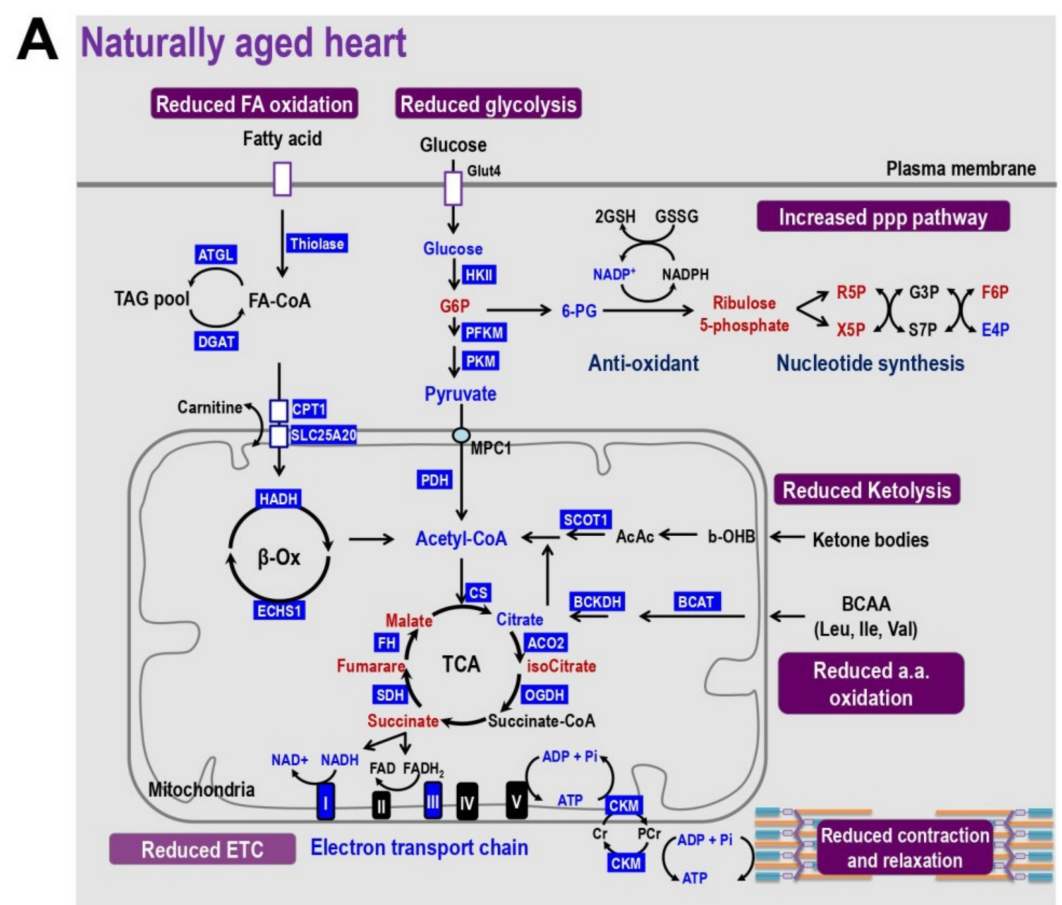

\section{B Longevity}

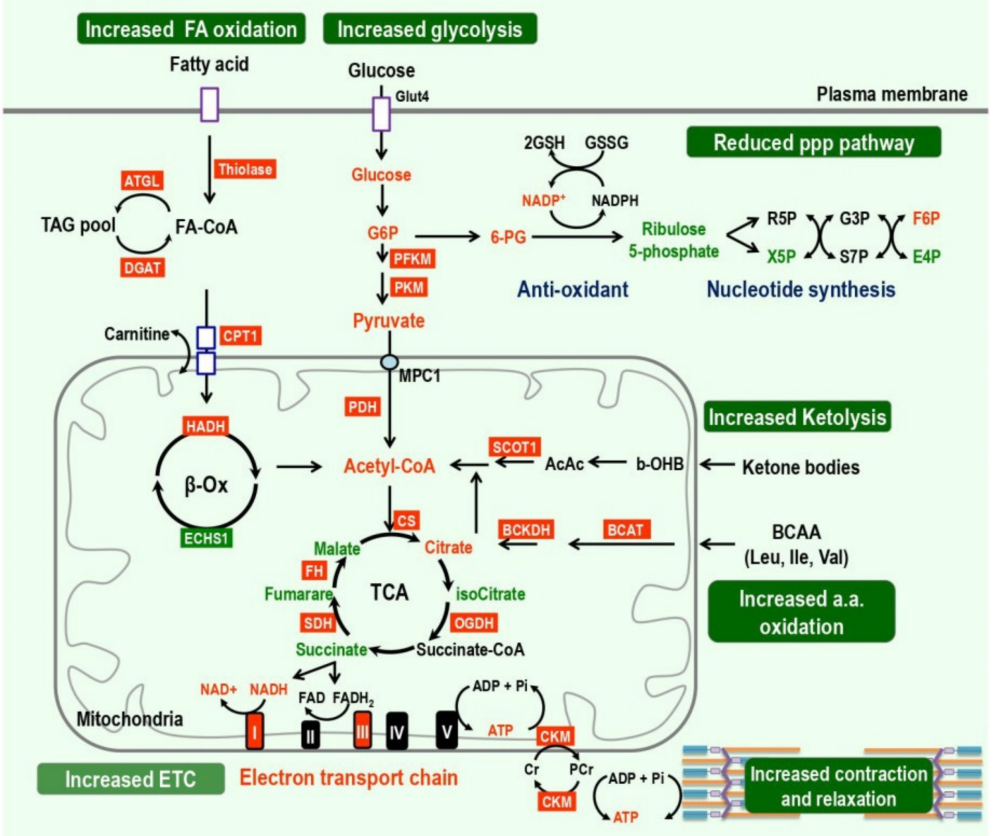

Figure 3. Cisd2 maintains a younger pattern of energy metabolism which is dysregulated in naturally aged heart. (A) Energy metabolism is disrupted during natural aging of wild-type (WT) mice. The results are obtained by comparing 24-mo WT vs. 3-mo WT mice. In the aged heart, the TCA cycle and ATP production are impaired due to decrease of fatty acid oxidation, ketolysis, glucose utilization, and amino acid oxidation. In addition, the creatinine shuttling of high-energy phosphate is also diminished in the aged heart. Blue and red colors mark the enzymes and metabolites that are downregulated or upregulated in the pathways, respectively. (B) Cisd2 maintains a younger pattern of 
energy metabolism in the heart of Cisd2TG mice, which is a long-lived mouse model. The results are obtained by comparing 24-mo Cisd2TG vs. 24-mo WT mice. Remarkably, in the Cisd2TG heart, there is an increase in the fatty acid oxidation, ketolysis, glucose utilization, and amino acid oxidation. Consequently, this appears to result in a normal cycling of the TCA and an increased activity of the electron transport chain to produce ATP. In addition, the creatinine shuttling of high-energy phosphate is also restored in the longevity heart. All together, these beneficial effects brought about by Cisd2 provide a sufficient energy supply to fuel the heart of the Cisd2TG mice. The levels of the enzymes and metabolites which have an opposite profile to that observed in the naturally aged heart are marked by green (down) and orange (up). In this study, alterations of metabolic pathways are summarized from omics analyses of metabolomics and transcriptomics of RNA sequencing using cardiac tissues of left ventricles.

In addition to the energy producing pathways, the pentose phosphate pathway seems also to be upregulated in the ageing heart. Previous studies have found that the activity of the key enzyme in this pathway, glucose-6-phosphate dehydrogenase (G6PD), is increased when cardiac hypertrophy is present $[83,84]$. In the naturally aged heart, our results have revealed that the metabolites G6P and ribulose 5-phosphate are significantly increased compared to young hearts (Figure 3A).

\subsubsection{Inefficient Ketone Body Metabolism}

Ketone bodies (KB), namely accumulated acetoacetate, beta-hydroxybutyrate, and acetone, are generated in liver via the ketogenesis pathway and are then released into plasma as fuel for many organs including the brain, heart, and muscle [85]. Since the consumption of free fatty acids is decreased in the ageing heart or in a heart with an age-related disease, ketone bodies are considered to be an "energy-efficient fuel" that produces more ATP from a small pool of substrates. Accumulating evidence has indicated that a ketone diet may have a beneficial effect on age-related diseases, and that cyclic ketone bodies probably have the ability to preserve the "young cardiac phenotype" in old mice [85-88]. Furthermore, in both mouse models and human patients, cardiomyocytes switch to ketone metabolism for oxidative ATP production when there is heart failure and hypertrophy $[89,90]$. Moreover, treatment with the cardiac protective compound empagliflozin has been shown to increase the level of ketone bodies in the plasma and to improve heart failure [91]. This further supports the cardioprotective role of ketone bodies. Therefore, elevated levels of ketone bodies in plasma and the utilization of ketone bodies by cardiomyocytes seem to enhance ATP production and improve cardiac functions in ageing hearts.

Notably, although ketone body metabolism is able to produce more ATP and support the ageing heart, the expression of a key enzyme, SCOT, has been found to decrease with age (Figure 3A). This indicates that the metabolism of ketone body remains less efficient in the older heart compared to the young heart. Indeed, increasing ketone oxidation in the heart, via enhanced levels of SCOT or other regulatory enzymes involved in ketolysis, has been proposed as a therapeutic target for improving cardiac functioning in a failing heart or when there is age-related cardiac dysfunction [92].

\subsubsection{Mitochondrial Dysfunction, Diminished OXPHOS, and Impaired FAO}

Fatty acids are the main energy source in a healthy young heart. However, the utilization of fatty acids declines with age [93,94]. In the normal heart, the signaling pathways related to peroxisome proliferator-activated receptors (PPARs) control fatty acid oxidation via targeting of pyruvate dehydrogenase kinase 4 and acetyl-CoA oxidase [95]. Age-related suppression of PPAR $\alpha$ results in decreased myocardial fatty acid metabolism and reduced ATP production, and then leads to lipid accumulation [69,96-100]. In addition, the activation of PPAR $\gamma$ signaling results in lipid accumulation and the impairment of FAO-related enzymes in the heart [101,102]. Age-related cardiac dysfunctions are usually accompanied by a decline in FAO rates. However, the uptake of fatty acids remains unchanged or can even be upregulated in some cases, which leads to lipid accumulation in cardiomyocytes [103-105]. Indeed, a previous study has showed that the expression of a fatty 
acid transporter, CD36, is increased in certain elderly populations [106]. An accumulation of lipids can generate toxic lipid species; this in turn has been reported to increase the ROS level and impair mitochondrial functioning. Moreover, such lipotoxicity may trigger inflammation, cell apoptosis, and mitochondrial dysfunction. This can eventually result in a vicious cycle that exacerbates age-related cardiac dysfunction and cardiomyopathy $[107,108]$.

In addition to a loss of metabolism flexibility and enhanced lipid accumulation in the ageing heart, the age-related structural alteration, and functional decline of the component proteins of ETC also contribute to decreased OXPHOS capacity. Complexes I, III, and IV play major roles in the transfer of electrons from NADH to generate the $\mathrm{H}^{+}$gradient for ATP production. During natural ageing of the heart, previous studies have reported that the functioning of complex I and complex III declines [59,109-111]. In agreement with this, our transcriptomics analysis of RNA sequencing data has revealed that the mRNA levels of several components of complex I and complex III are significantly decreased in old mice at 24-mo old (Figure 3A).

\subsection{Cisd2 Delays Cardiac Ageing and Maintains a Younger Metabolism during Old Age}

The expression level of Cisd2 decreases during cardiac ageing. Cisd2 deficiency causes cardiac dysfunction and accelerates cardiac ageing. Conversely, a persistently high level of Cisd2 attenuates age-related structural damage and the related functional decline [19]. Intriguingly, in the hearts of Cisd2TG mice at 24-mo old, the metabolic dysregulation in energy production and loss of metabolic flexibility associated with age is significantly improved. Remarkably, the majority of differentially expressed proteins (enzymes or transporters) and their relevant metabolites, including abnormally upregulated and downregulated genes and various metabolites, appear to have their age-associated changes in expression reversed in the heart of Cisd2TG mice, which have a more than 2-fold higher expression level of Cisd2 in their heart compared with age-matched and sex-matched WT mice. We have made the following discoveries based on our analysis of our transcriptomics and metabolomics data. Firstly, the decline in creatine kinase (CKM), which is involved in the PCr energy shuttle, is reversed in Cisd2TG mice; this indicates that the "creatine kinase-phosphocreatine energy shuttle" remains functional and is able to carry out the energy transfer and storage of high-energy phosphate compounds. Secondly, the expression levels of genes involved in the FAO and glycolysis, which are significantly decreased in naturally aged heart, are upregulated in the Cisd2TG mice. Thirdly, the decline in expression level of SCOT, a vital enzyme in ketone metabolism, is reversed in the Cisd2TG mice. Finally, in the Cisd2TG mice, the TCA cycle and mitochondrial ETC (especially complex I and complex III) also show a reversal in their decline compared to aged WT mice (Figure 3B). These findings reveal that a proper regulation of energy metabolism and a dynamic control of metabolic flexibility are retained in the hearts of Cisd2TG mice and thus a higher level of Cisd2 is able to delay cardiac ageing and maintain "a younger cardiac metabolic profile".

\section{Conclusions and Perspective}

Hundreds of potential antiageing compounds have been reported. Geroprotectors need to fulfill a number of important criteria. Firstly, they should extend lifespan in multiple species and/or different strains of a mammalian animal model. Secondly, they should lessen the human biomarkers of ageing. Thirdly, they need to have minimal side effects and an acceptable toxicity level. Fourthly, they should improve health-related quality of life. Fifthly, they should increase stress resistance. Finally, they should protect against age-related diseases [112-115]. Many geroprotectors, such as rapamycin, resveratrol, metformin, and various senolytics (e.g., fisetin, dasatininb, and querectin) that are able to remove senescent cells have been reported to improve age-related phenotypes in multiple organs/tissues and/or biological process [115-120]. The "National Institute on Ageing Interventions Testing Program" has carried out several trials with the aim of finding potential interventions that can extend the lifespan of genetically heterogeneous mice. The compounds tested can be classed into three groups. The first group consists of acarbose [121], glycine [122], and rapamycin [123]; these three compounds 
are able to increase lifespan in both males and females. The second group consists of aspirin [124], nordihydroguaiaretic acid [124], protandim [121], and 17 $\alpha$-estradiol [121]; these four compounds are able to increase lifespan in males only. Finally, there is a third group of compounds that were found not to have the ability to extend lifespan and these include metformin, curcumin, and simvastatin [112].

The prolongevity gene Cisd 2 is a novel target for geroprotectors and such an approach ought to promote healthy ageing and prevent age-related diseases (Figure 4). Our previous studies and the new evidence provided here highlight Cisd2 as a novel drug target when developing therapies to delay cardiac ageing and ameliorate age-related cardiac diseases.
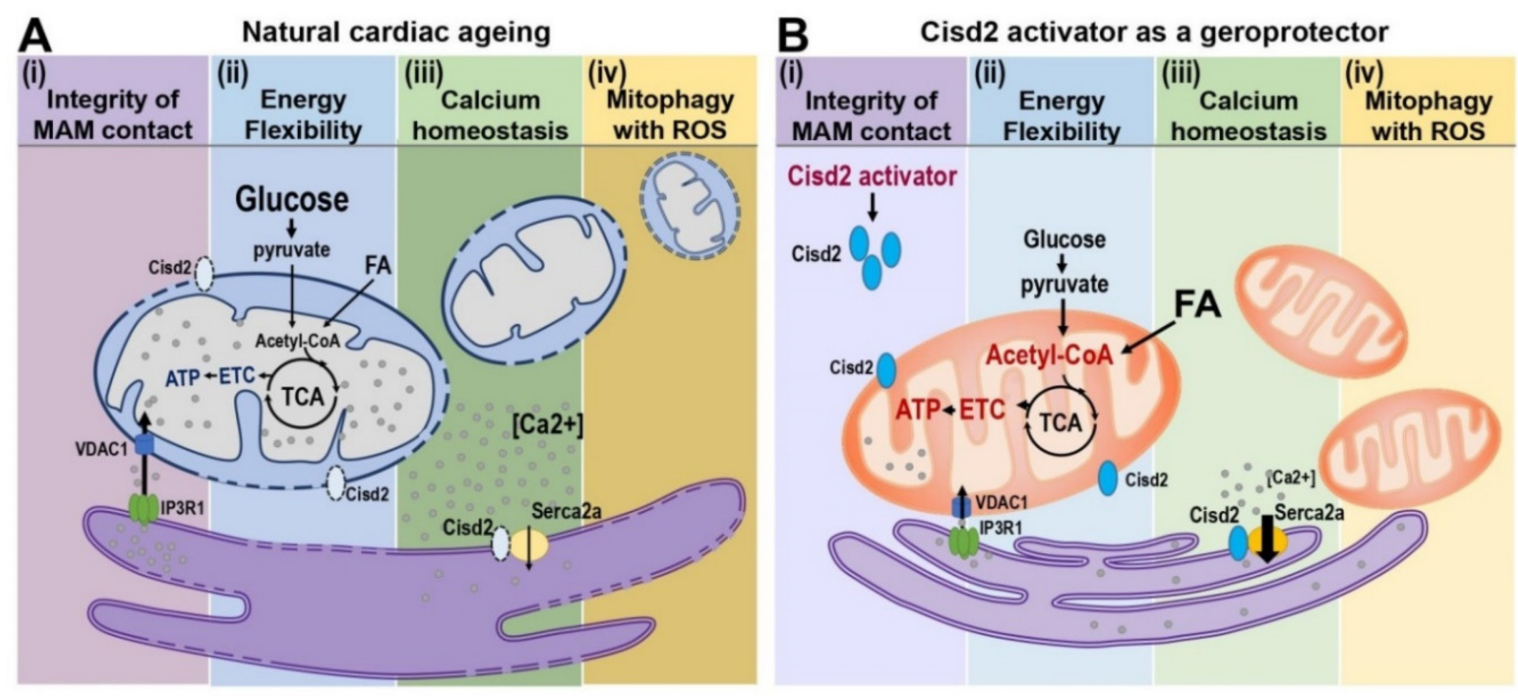

Figure 4. Cisd2 preserves the structure and function of MAM during cardiac ageing. (A) Four characters of mitochondria-related dysfunction are identified during cardiac ageing: (i) Disruption of integrity of MAM contact sites. Physical proximity and functional interplay between mitochondria and SR are disturbed during cardiac ageing; this is associated with a widened gap distance between ER and mitochondria leading to an abnormal $\mathrm{Ca}^{2+}$ signaling and lipid transport. (ii) Dysregulation of energy flexibility. More than $95 \%$ of cardiac ATP is produced from the oxidative phosphorylation of mitochondria via electron transfer chain (ETC), which is fueled with energy primarily from $\beta$-oxidation of fatty acids (FA) and to a lesser extent from glycolysis of glucose. Defective fatty acid oxidation of mitochondria jeopardizes the energy flexibility of cardiomyocytes. (iii) $\mathrm{Ca}^{2+}$ dyshomeostasis. Elevated cytosolic $\mathrm{Ca}^{2+}$ levels resulted from the defective $\mathrm{Ca}^{2+}$ recruitment of ER and decreased $\mathrm{Ca}^{2+}$ influx capacity of mitochondria as well as impaired cellular $\mathrm{Ca}^{2+}$ extrusions are detectable in aged hearts. (iv) Disturbance of mitophagy accompanied with increased ROS. Decrease in the capacity of lysosomal degradation pathway and mitochondrial biogenesis, as well as decrease in mitophagy are observed in aged hearts. Furthermore, these defects usually associated with increased oxidative stress. (B) Cisd2 activator as a geroprotector to increase Cisd2 and to preserve cardiac function during ageing. Cisd2 is mainly located in the ER, mitochondria, and MAM. The expression level of Cisd 2 decreases during cardiac ageing. A high level of Cisd 2 achieved by treatment of Cisd2 activators probably can attenuate these abnormalities during cardiac ageing.

Author Contributions: All the authors contributed to the manuscript preparation. C.-H.Y. codesigned the topics and manuscript structure, prepared the figures, and drafted the manuscript. Y.-J.C. contributed to the writing of metabolic reprogramming and prepared the figures. C.-H.K. designed, conducted, and prepared the TEM results. T.-F.T. designed the topics and manuscript structure and wrote the final manuscript. All authors have read and agreed to the published version of the manuscript.

Funding: This research was supported provided by grants from the Ministry of Science and Technology (MOST107-2314-B-182A-160-MY3 and MOST109-2320-B-182A-020 to CHY; MOST 109-2320-B-010-043 and MOST 109-2634-F-010-003 to TFT), and from Chang Gung Memorial Hospital (CMRPD5J0021 to CHK; CORPG2H0041-0043 and CMRPG2H000091-0093 to CHY). 
Acknowledgments: We thank the following core facilities: Genomics Center for Clinical and Biotechnological Applications of National Core Facility for Biopharmaceuticals, Taiwan (MOST 109-2740-B-010-002) for RNA sequencing; Healthy Aging Research Center at Chang Gung University for their metabolomics analysis; Microscopy Center at Chang Gung University for their technical assistance on TEM.

Conflicts of Interest: The authors declare no conflict of interest.

\section{Abbreviations}

\begin{tabular}{|c|c|}
\hline Glut4 & Glucose transporter type 4 \\
\hline HKII & Hexokinase II \\
\hline G6P & Glucose-6-phosphate \\
\hline PFKM & ATP-dependent 6-phosphofructokinase \\
\hline PKM & Pyruvate kinase \\
\hline MPC1 & Mitochondrial pyruvate carrier 1 \\
\hline $\mathrm{PDH}$ & Pyruvate dehydrogenase \\
\hline CS & Citrate synthase \\
\hline ACO2 & Aconitase 2 \\
\hline OGDH & Oxoglutarate Dehydrogenase \\
\hline $\mathrm{SDH}$ & Subunit of succinate dehydrogenase \\
\hline $\mathrm{FH}$ & Fumarate Hydratase \\
\hline NAD+ & Nicotinamide adenine dinucleotide \\
\hline NADH & Nicotinamide adenine dinucleotide \\
\hline FAD+ & Flavin adenine dinucleotide \\
\hline FADH2 & Reduced flavin adenine dinucleotide \\
\hline ETC & Electron transfer chain \\
\hline ATP & Adenosine triphosphate \\
\hline ADP & Adenosine di-phosphate \\
\hline 6-PG & 6-phosphogluconate \\
\hline R5P & Ribose 5-phosphate \\
\hline $\mathrm{X} 5 \mathrm{P}$ & Xylulose 5-phosphate \\
\hline G3P & Glyceraldehyde 3-phosphate \\
\hline S7P & Sedoheptulose 7-phosphate \\
\hline F3P & Fructose 6-phosphate \\
\hline $\mathrm{E} 4 \mathrm{P}$ & Erythrose 4-phosphate \\
\hline ATGL & Adipose triglyceride lipase \\
\hline DGAT & Diacylglycerol O-Acyltransferase \\
\hline CPT1 & Carnitine palmitoyltransferase I \\
\hline SLC25A20 & Solute Carrier Family 25 Member 20 \\
\hline $\mathrm{HADH}$ & Hydroxyacyl-coenzyme A dehydrogenase \\
\hline ECHS & Enoyl-CoA hydratase \\
\hline SCOT1 & Succinyl-CoA-3-oxaloacid CoA transferase \\
\hline BCAA & Branched-chain amino acids \\
\hline $\mathrm{BCKDH}$ & Branched Chain Keto Acid Dehydrogenase E1 \\
\hline BCAT & Branched-chain amino acid aminotransferase \\
\hline Leu & Leucine \\
\hline Ile & Isoleucine \\
\hline Val & Valine \\
\hline a.a. & Amino acid \\
\hline AcAc & Acetylacetonate \\
\hline b-OHB & Beta-hydroxybutyrate \\
\hline$\beta-O x$ & Beta oxidation \\
\hline GSH & Glutathione \\
\hline GSSG & Glutathione disulfide \\
\hline
\end{tabular}




$\begin{array}{ll}\text { MAM } & \text { Mitochondria-associated membrane } \\ \text { ER } & \text { Endoplasmic reticulum } \\ \text { ROS } & \text { Reactive oxygen species } \\ \text { TEM } & \text { Transmission electron microscopy } \\ {\left[\mathrm{Ca}^{2+}\right] \mathrm{i}} & \text { Intracellular } \mathrm{Ca}^{2+} \text { concentration } \\ \text { MCU } & \text { Mitochondrial } \mathrm{Ca}^{2+} \text { uniporter } \\ \text { NCX } & \text { Na+/Ca }{ }^{2+} \text { exchanger } \\ \text { TCA cycle } & \text { Tricarboxylic acid cycle } \\ \text { IP3Rs } & \text { Inositol 1,4,5-trisphosphate receptors } \\ \text { VDAC } & \text { Voltagedependent anionselective channel } \\ \text { GRP75 } & \text { Chaperone 75kDa glucoseregulated protein } \\ \text { RYR } & \text { Ryanodine receptor } \\ \text { Gimap5 } & \text { GTPase of immune-associated protein 5 } \\ \text { PNM } & \text { Perinuclear mitochondria } \\ \text { SSM } & \text { Subsarcolemmal mitochondria } \\ \text { IFMs } & \text { Interfibrillar mitochondria } \\ \text { OMM } & \text { Mitochondrial outer membrane } \\ \text { OXPHOS } & \text { Oxidative phosphorylation } \\ \text { FAO } & \text { Fatty acid oxidation } \\ \text { PCr } & \text { Phosphocreatine } \\ \text { PPP } & \text { Pentose phosphate pathway } \\ \text { PPARs } & \text { Peroxisome proliferator-activated receptors } \\ \text { PFK1 } & \text { ATP-dependent 6-phosphofructokinase } \\ \text { G6PD } & \text { Glucose-6-phosphate dehydrogenase } \\ \text { KB } & \text { Ketone bodies }\end{array}$

\section{References}

1. Virani, S.S.; Alonso, A.; Benjamin, E.J.; Bittencourt, M.S.; Callaway, C.W.; Carson, A.P.; Chamberlain, A.M.; Chang, A.R.; Cheng, S.; Delling, F.N.; et al. Heart Disease and Stroke Statistics-2020 Update: A Report from the American Heart Association. Circulation 2020, 141, e139-e596. [CrossRef] [PubMed]

2. Li, H.; Hastings, M.H.; Rhee, J.; Trager, L.E.; Roh, J.D.; Rosenzweig, A. Targeting age-related pathways in heart failure. Circ. Res. 2020, 126, 533-551. [CrossRef] [PubMed]

3. Li, J.; Zhang, D.; Brundel, B.; Wiersma, M. Imbalance of ER and mitochondria interactions: Prelude to cardiac ageing and disease? Cells 2019, 8, 1617. [CrossRef] [PubMed]

4. Lakatta, E.G. So! What's aging? Is cardiovascular aging a disease? J. Mol. Cell Cardiol. 2015, 83, 1-13. [CrossRef] [PubMed]

5. Lee, K.-S.; Huh, S.; Lee, S.; Wu, Z.; Kim, A.-K.; Kang, H.-Y.; Lu, B. Altered ER-mitochondria contact impacts mitochondria calcium homeostasis and contributes to neurodegeneration in vivo in disease models. Proc. Natl. Acad. Sci. USA 2018, 115, E8844-E8853. [CrossRef]

6. Martin, N.; Bernard, D. Calcium signaling and cellular senescence. Cell Calcium 2018, 70, 16-23. [CrossRef]

7. Shi, R.; Guberman, M.; Kirshenbaum, L.A. Mitochondrial quality control: The role of mitophagy in aging. Trends Cardiovasc. Med. 2018, 28, 246-260. [CrossRef]

8. Wu, N.N.; Zhang, Y.; Ren, J. Mitophagy, mitochondrial dynamics, and homeostasis in cardiovascular aging. Oxid. Med. Cell Longev. 2019, 2019, 9825061. [CrossRef]

9. Karwi, Q.G.; Uddin, G.M.; Ho, K.L.; Lopaschuk, G.D. Loss of metabolic flexibility in the failing heart. Front. Cardiovasc. Med. 2018, 5, 68. [CrossRef]

10. Nathania, M.; Hollingsworth, K.G.; Bates, M.; Eggett, C.; Trenell, M.I.; Velicki, L.; Seferovic, P.M.; MacGowan, G.A.; Turnbull, D.M.; Jakovljevic, D.G. Impact of age on the association between cardiac high-energy phosphate metabolism and cardiac power in women. Heart 2018, 104, 111-118. [CrossRef]

11. Fan, Y.; Simmen, T. Mechanistic Connections between Endoplasmic Reticulum (ER) redox control and mitochondrial metabolism. Cells 2019, 8, 1071. [CrossRef] [PubMed]

12. Lopez-Otin, C.; Blasco, M.A.; Partridge, L.; Serrano, M.; Kroemer, G. The hallmarks of aging. Cell 2013, 153, 1194-1217. [CrossRef] [PubMed] 
13. Silva-Palacios, A.; Zazueta, C.; Pedraza-Chaverri, J. ER membranes associated with mitochondria: Possible therapeutic targets in heart-associated diseases. Pharmacol. Res. 2020, 156, 104758. [CrossRef] [PubMed]

14. Prinz, W.A.; Toulmay, A.; Balla, T. The functional universe of membrane contact sites. Nat. Rev. Mol. Cell Biol. 2020, 21, 7-24. [CrossRef] [PubMed]

15. Janikiewicz, J.; Szymanski, J.; Malinska, D.; Patalas-Krawczyk, P.; Michalska, B.; Duszynski, J.; Giorgi, C.; Bonora, M.; Dobrzyn, A.; Wieckowski, M.R. Mitochondria-associated membranes in aging and senescence: Structure, function, and dynamics. Cell Death Dis. 2018, 9, 332. [CrossRef]

16. Giorgi, C.; Missiroli, S.; Patergnani, S.; Duszynski, J.; Wieckowski, M.R.; Pinton, P. Mitochondria-associated membranes: Composition, molecular mechanisms, and physiopathological implications. Antioxid. Redox Signal. 2015, 22, 995-1019. [CrossRef]

17. Chen, Y.F.; Kao, C.H.; Chen, Y.T.; Wang, C.H.; Wu, C.Y.; Tsai, C.Y.; Liu, F.C.; Yang, C.W.; Wei, Y.H.; Hsu, M.T. Cisd2 deficiency drives premature aging and causes mitochondria-mediated defects in mice. Genes Dev. 2009, 23, 1183-1194. [CrossRef]

18. Shen, Z.Q.; Chen, Y.F.; Chen, J.R.; Jou, Y.S.; Wu, P.C.; Kao, C.H.; Wang, C.H.; Huang, Y.L.; Chen, C.F.; Huang, T.S. CISD2 Haploinsufficiency Disrupts Calcium Homeostasis, Causes Nonalcoholic Fatty Liver Disease, and Promotes Hepatocellular Carcinoma. Cell Rep. 2017, 21, 2198-2211. [CrossRef]

19. Yeh, C.H.; Shen, Z.Q.; Hsiung, S.Y.; Wu, P.C.; Teng, Y.C.; Chou, Y.J.; Fang, S.W.; Chen, C.F.; Yan, Y.T.; Kao, L.S. Cisd2 is essential to delaying cardiac aging and to maintaining heart functions. PLoS Biol. 2019, 17, e3000508. [CrossRef]

20. Chen, Y.F.; Kao, C.H.; Kirby, R.; Tsai, T.F. Cisd2 mediates mitochondrial integrity and life span in mammals. Autophagy 2009, 5, 1043-1045. [CrossRef]

21. Wang, C.H.; Chen, Y.F.; Wu, C.Y.; Wu, P.C.; Huang, Y.L.; Kao, C.H.; Lin, C.H.; Kao, L.S.; Tsai, T.F.; Wei, Y.H. Cisd2 modulates the differentiation and functioning of adipocytes by regulating intracellular Ca2+ homeostasis. Hum. Mol. Genet. 2014, 23, 4770-4785. [CrossRef] [PubMed]

22. Huang, Y.L.; Shen, Z.Q.; Wu, C.Y.; Teng, Y.C.; Liao, C.C.; Kao, C.H.; Chen, L.K.; Lin, C.H.; Tsai, T.F. Comparative proteomic profiling reveals a role for Cisd2 in skeletal muscle aging. Aging Cell 2018, 17, e12705. [CrossRef] [PubMed]

23. Chen, Y.F.; Chou, T.Y.; Lin, I.H.; Chen, C.G.; Kao, C.H.; Huang, G.J.; Chen, L.K.; Wang, P.N.; Lin, C.P.; Tsai, T.F. Upregulation of Cisd2 attenuates Alzheimer's-related neuronal loss in mice. J. Pathol. 2020, 250, $299-311$. [CrossRef] [PubMed]

24. Picca, A.; Mankowski, R.T.; Burman, J.L.; Donisi, L.; Kim, J.S.; Marzetti, E.; Leeuwenburgh, C. Mitochondrial quality control mechanisms as molecular targets in cardiac ageing. Nat. Rev. Cardiol. 2018, 15, 543-554. [CrossRef] [PubMed]

25. Dutta, D.; Calvani, R.; Bernabei, R.; Leeuwenburgh, C.; Marzetti, E. Contribution of impaired mitochondrial autophagy to cardiac aging: Mechanisms and therapeutic opportunities. Circ. Res. 2012, 110, 1125-1138. [CrossRef] [PubMed]

26. Moreno-Garcia, A.; Kun, A.; Calero, O.; Medina, M.; Calero, M. An Overview of the Role of Lipofuscin in Age-Related Neurodegeneration. Front. Neurosci. 2018, 12, 464. [CrossRef]

27. Kakimoto, Y.; Okada, C.; Kawabe, N.; Sasaki, A.; Tsukamoto, H.; Nagao, R.; Osawa, M. Myocardial lipofuscin accumulation in ageing and sudden cardiac death. Sci. Rep. 2019, 9, 3304. [CrossRef]

28. Rietdorf, K.; Coode, E.E.; Schulz, A.; Wibbeler, E.; Bootman, M.D.; Ostergaard, J.R. Cardiac pathology in neuronal ceroid lipofuscinoses (NCL): More than a mere co-morbidity. Biochim. Biophys. Acta Mol. Basis Dis. 2020, 1866, 165643. [CrossRef]

29. Østergaard, J.R.; Rasmussen, T.B.; Mølgaard, H. Cardiac involvement in juvenile neuronal ceroid lipofuscinosis (Batten disease). Neurology 2011, 76, 1245-1251. [CrossRef]

30. Olson, M.L.; Chalmers, S.; McCarron, J.G. Mitochondrial organization and Ca2+ uptake. Biochem. Soc. Trans. 2012, 40, 158-167. [CrossRef]

31. Lopes, G.S.; Ferreira, A.T.; Oshiro, M.E.; Vladimirova, I.; Jurkiewicz, N.H.; Jurkiewicz, A.; Smaili, S.S. Aging-related changes of intracellular $\mathrm{Ca} 2+$ stores and contractile response of intestinal smooth muscle. Exp. Gerontol. 2006, 41, 55-62. [CrossRef] [PubMed]

32. Behringer, E.J.; Segal, S.S. Impact of aging on calcium signaling and membrane potential in endothelium of resistance arteries: A role for mitochondria. J. Gerontol. A Biol. Sci. Med. Sci. 2017, 72, 1627-1637. [CrossRef] [PubMed] 
33. Nobili, A.; Krashia, P.; D'Amelio, M. Cisd2: A promising new target in Alzheimer's disease. J. Pathol. 2020, 251, 113-116. [CrossRef] [PubMed]

34. Patergnani, S.; Suski, J.M.; Agnoletto, C.; Bononi, A.; Bonora, M.; De Marchi, E.; Giorgi, C.; Marchi, S.; Missiroli, S.; Poletti, F.; et al. Calcium signaling around mitochondria associated membranes (MAMs). Cell Commun. Signal. 2011, 9, 19. [CrossRef] [PubMed]

35. Jiang, D.; Zhao, L.; Clapham, D.E. Genome-wide RNAi screen identifies Letm1 as a mitochondrial Ca2+/H+ antiporter. Science 2009, 326, 144-147. [CrossRef]

36. Kirichok, Y.; Krapivinsky, G.; Clapham, D.E. The mitochondrial calcium uniporter is a highly selective ion channel. Nature 2004, 427, 360-364. [CrossRef]

37. Palty, R.; Silverman, W.F.; Hershfinkel, M.; Caporale, T.; Sensi, S.L.; Parnis, J.; Nolte, C.; Fishman, D.; Shoshan-Barmatz, V.; Herrmann, S.; et al. NCLX is an essential component of mitochondrial Na+/Ca2+ exchange. Proc. Natl. Acad. Sci. USA 2010, 107, 436-441. [CrossRef]

38. Krols, M.; van Isterdael, G.; Asselbergh, B.; Kremer, A.; Lippens, S.; Timmerman, V.; Janssens, S. Mitochondria-associated membranes as hubs for neurodegeneration. Acta Neuropathol. 2016, 131, 505-523. [CrossRef]

39. Cali, T.; Ottolini, D.; Negro, A.; Brini, M. Enhanced parkin levels favor ER-mitochondria crosstalk and guarantee $\mathrm{Ca}(2+)$ transfer to sustain cell bioenergetics. Biochim. Biophys. Acta 2013, 1832, 495-508. [CrossRef]

40. Missiroli, S.; Danese, A.; Iannitti, T.; Patergnani, S.; Perrone, M.; Previati, M.; Giorgi, C.; Pinton, P. Endoplasmic reticulum-mitochondria $\mathrm{Ca}(2+)$ crosstalk in the control of the tumor cell fate. Biochim. Biophys. Acta Mol. Cell Res. 2017, 1864, 858-864. [CrossRef]

41. Missiroli, S.; Patergnani, S.; Caroccia, N.; Pedriali, G.; Perrone, M.; Previati, M.; Wieckowski, M.R.; Giorgi, C. Mitochondria-associated membranes (MAMs) and inflammation. Cell Death Dis. 2018, 9, 329. [CrossRef] [PubMed]

42. Han, J.M.; Periwal, V. A mathematical model of calcium dynamics: Obesity and mitochondria-associated ER membranes. PLoS Comput. Biol. 2019, 15, e1006661. [CrossRef] [PubMed]

43. Arruda, A.P.; Pers, B.M.; Parlakgül, G.; Güney, E.; Inouye, K.; Hotamisligil, G.S. Chronic enrichment of hepatic endoplasmic reticulum-mitochondria contact leads to mitochondrial dysfunction in obesity. Nat. Med. 2014, 20, 1427-1435. [CrossRef] [PubMed]

44. Rowland, A.A.; Voeltz, G.K. Endoplasmic reticulum-mitochondria contacts: Function of the junction. Nat. Rev. Mol. Cell Biol. 2012, 13, 607-625. [CrossRef] [PubMed]

45. Zhang, X.; Gibhardt, C.S.; Will, T.; Stanisz, H.; Korbel, C.; Mitkovski, M.; Stejerean, I.; Cappello, S.; Pacheu-Grau, D.; Dudek, J.; et al. Redox signals at the ER-mitochondria interface control melanoma progression. EMBO J. 2019, 38, e100871. [CrossRef] [PubMed]

46. Csordas, G.; Varnai, P.; Golenar, T.; Roy, S.; Purkins, G.; Schneider, T.G.; Balla, T.; Hajnoczky, G. Imaging interorganelle contacts and local calcium dynamics at the ER-mitochondrial interface. Mol. Cell 2010, 39, 121-132. [CrossRef]

47. Csordas, G.; Weaver, D.; Hajnoczky, G. Endoplasmic Reticulum-Mitochondrial Contactology: Structure and Signaling Functions. Trends Cell Biol. 2018, 28, 523-540. [CrossRef]

48. Dorn, G.W., II; Song, M.; Walsh, K. Functional implications of mitofusin 2-mediated mitochondrial-SR tethering. J. Mol. Cell Cardiol. 2015, 78, 123-128. [CrossRef]

49. Gutiérrez, T.; Parra, V.; Troncoso, R.; Pennanen, C.; Contreras-Ferrat, A.; Vasquez-Trincado, C.; Morales, P.E.; Lopez-Crisosto, C.; Sotomayor-Flores, C.; Chiong, M.; et al. Alteration in mitochondrial Ca2+ uptake disrupts insulin signaling in hypertrophic cardiomyocytes. Cell Commun. Signal. 2014, 12, 68. [CrossRef]

50. Lopez-Crisosto, C.; Pennanen, C.; Vasquez-Trincado, C.; Morales, P.E.; Bravo-Sagua, R.; Quest, A.F.G.; Chiong, M.; Lavandero, S. Sarcoplasmic reticulum-mitochondria communication in cardiovascular pathophysiology. Nat. Rev. Cardiol. 2017, 14, 342-360. [CrossRef]

51. Wang, C.H.; Kao, C.H.; Chen, Y.F.; Wei, Y.H.; Tsai, T.F. Cisd2 mediates lifespan: Is there an interconnection among $\mathrm{Ca}(2)(+)$ homeostasis, autophagy, and lifespan? Free Radic. Res. 2014, 48, 1109-1114. [CrossRef] [PubMed]

52. Chang, N.C.; Nguyen, M.; Germain, M.; Shore, G.C. Antagonism of Beclin 1-dependent autophagy by BCL-2 at the endoplasmic reticulum requires NAF-1. EMBO J. 2010, 29, 606-618. [CrossRef] [PubMed] 
53. Chang, N.C.; Nguyen, M.; Bourdon, J.; Risse, P.-A.; Martin, J.; Danialou, G.; Rizzuto, R.; Petrof, B.J.; Shore, G.C. Bcl-2-associated autophagy regulator Naf-1 required for maintenance of skeletal muscle. Hum. Mol. Genet. 2012, 21, 2277-2287. [CrossRef] [PubMed]

54. Cao, Y.P.; Zheng, M. Mitochondrial dynamics and inter-mitochondrial communication in the heart. Arch. Biochem. Biophys. 2019, 663, 214-219. [CrossRef] [PubMed]

55. Ong, S.B.; Hall, A.R.; Hausenloy, D.J. Mitochondrial dynamics in cardiovascular health and disease. Antioxid. Redox Signal. 2013, 19, 400-414. [CrossRef] [PubMed]

56. Suh, J.H.; Shigeno, E.T.; Morrow, J.D.; Cox, B.; Rocha, A.E.; Frei, B.; Hagen, T.M. Oxidative stress in the aging rat heart is reversed by dietary supplementation with (R)-(alpha)-lipoic acid. FASEB J. 2001, 15, 700-706. [CrossRef]

57. Suh, J.H.; Heath, S.H.; Hagen, T.M. Two subpopulations of mitochondria in the aging rat heart display heterogenous levels of oxidative stress. Free Radic. Biol. Med. 2003, 35, 1064-1072. [CrossRef]

58. Ulasova, E.; Gladden, J.D.; Chen, Y.; Zheng, J.; Pat, B.; Bradley, W.; Powell, P.; Zmijewski, J.W.; Zelickson, B.R.; Ballinger, S.W.; et al. Loss of interstitial collagen causes structural and functional alterations of cardiomyocyte subsarcolemmal mitochondria in acute volume overload. J. Mol. Cell Cardiol. 2011, 50, 147-156. [CrossRef]

59. Lesnefsky, E.J.; Chen, Q.; Hoppel, C.L. Mitochondrial Metabolism in Aging Heart. Circ. Res. 2016, 118, 1593-1611. [CrossRef]

60. Stotland, A.; Gottlieb, R.A. $\alpha$-MHC MitoTimer mouse: In vivo mitochondrial turnover model reveals remarkable mitochondrial heterogeneity in the heart. J. Mol. Cell Cardiol. 2016, 90, 53-58. [CrossRef]

61. Boengler, K.; Stahlhofen, S.; van de Sand, A.; Gres, P.; Ruiz-Meana, M.; Garcia-Dorado, D.; Heusch, G.; Schulz, R. Presence of connexin 43 in subsarcolemmal, but not in interfibrillar cardiomyocyte mitochondria. Basic Res. Cardiol. 2009, 104, 141-147. [CrossRef] [PubMed]

62. Giacomello, M.; Pellegrini, L. The coming of age of the mitochondria-ER contact: A matter of thickness. Cell Death Differ. 2016, 23, 1417-1427. [CrossRef] [PubMed]

63. Qi, H.; Li, L.; Shuai, J. Optimal microdomain crosstalk between endoplasmic reticulum and mitochondria for Ca2+ oscillations. Sci. Rep. 2015, 5, 7984. [CrossRef]

64. Moshkforoush, A.; Ashenagar, B.; Tsoukias, N.M.; Alevriadou, B.R. Modeling the role of endoplasmic reticulum-mitochondria microdomains in calcium dynamics. Sci. Rep. 2019, 9, 17072. [CrossRef] [PubMed]

65. Pinton, P.; Rimessi, A.; Marchi, S.; Orsini, F.; Migliaccio, E.; Giorgio, M.; Contursi, C.; Minucci, S.; Mantovani, F.; Wieckowski, M.R.; et al. Protein kinase $\mathrm{C}$ beta and prolyl isomerase 1 regulate mitochondrial effects of the life-span determinant p66Shc. Science 2007, 315, 659-663. [CrossRef]

66. Calvo-Rodriguez, M.; Garcia-Durillo, M.; Villalobos, C.; Nunez, L. In vitro aging promotes endoplasmic reticulum (ER)-mitochondria $\mathrm{Ca}(2+)$ cross talk and loss of store-operated $\mathrm{Ca}(2+)$ entry (SOCE) in rat hippocampal neurons. Biochim. Biophys. Acta 2016, 1863, 2637-2649. [CrossRef]

67. Wiel, C.; Lallet-Daher, H.; Gitenay, D.; Gras, B.; Le Calve, B.; Augert, A.; Ferrand, M.; Prevarskaya, N.; Simonnet, H.; Vindrieux, D.; et al. Endoplasmic reticulum calcium release through ITPR2 channels leads to mitochondrial calcium accumulation and senescence. Nat. Commun. 2014, 5, 3792. [CrossRef]

68. Gao, P.; Jiang, Y.; Wu, H.; Sun, F.; Li, Y.; He, H.; Wang, B.; Lu, Z.; Hu, Y.; Wei, X.; et al. Inhibition of Mitochondrial Calcium Overload by SIRT3 Prevents Obesity- or Age-Related Whitening of Brown Adipose Tissue. Diabetes 2020, 69, 165-180. [CrossRef]

69. Drosatos, K. Fatty old hearts: Role of cardiac lipotoxicity in age-related cardiomyopathy. Pathobiol. Aging Age Relat. Dis. 2016, 6, 32221. [CrossRef]

70. Lopaschuk, G.D.; Ussher, J.R.; Folmes, C.D.; Jaswal, J.S.; Stanley, W.C. Myocardial fatty acid metabolism in health and disease. Physiol. Rev. 2010, 90, 207-258. [CrossRef]

71. Stanley, W.C.; Recchia, F.A.; Lopaschuk, G.D. Myocardial substrate metabolism in the normal and failing heart. Physiol. Rev. 2005, 85, 1093-1129. [CrossRef] [PubMed]

72. Stanley, W.C. Cardiac energetics during ischaemia and the rationale for metabolic interventions. Coron. Artery Dis. 2001, 12 (Suppl. S1), S3-S7. [PubMed]

73. Fragasso, G. Age-related reduction of myocardial metabolic efficiency: Is it time to routinely measure myocardial metabolism to monitor cardiac health? Heart 2018, 104, 88-89. [CrossRef] [PubMed]

74. Nascimben, L.; Ingwall, J.S.; Lorell, B.H.; Pinz, I.; Schultz, V.; Tornheim, K.; Tian, R. Mechanisms for increased glycolysis in the hypertrophied rat heart. Hypertension 2004, 44, 662-667. [CrossRef] 
75. Kolwicz, S.C., Jr.; Purohit, S.; Tian, R. Cardiac metabolism and its interactions with contraction, growth, and survival of cardiomyocytes. Circ. Res. 2013, 113, 603-616. [CrossRef]

76. Pound, K.M.; Sorokina, N.; Ballal, K.; Berkich, D.A.; Fasano, M.; Lanoue, K.F.; Taegtmeyer, H.; O'Donnell, J.M.; Lewandowski, E.D. Substrate-enzyme competition attenuates upregulated anaplerotic flux through malic enzyme in hypertrophied rat heart and restores triacylglyceride content: Attenuating upregulated anaplerosis in hypertrophy. Circ. Res. 2009, 104, 805-812. [CrossRef] [PubMed]

77. Sorokina, N.; O’Donnell, J.M.; McKinney, R.D.; Pound, K.M.; Woldegiorgis, G.; LaNoue, K.F.; Ballal, K.; Taegtmeyer, H.; Buttrick, P.M.; Lewandowski, E.D. Recruitment of compensatory pathways to sustain oxidative flux with reduced carnitine palmitoyltransferase I activity characterizes inefficiency in energy metabolism in hypertrophied hearts. Circulation 2007, 115, 2033-2041. [CrossRef]

78. Shao, D.; Tian, R. Glucose Transporters in Cardiac Metabolism and Hypertrophy. Compr. Physiol. 2015, 6, 331-351. [CrossRef]

79. Allard, M.F.; Schonekess, B.O.; Henning, S.L.; English, D.R.; Lopaschuk, G.D. Contribution of oxidative metabolism and glycolysis to ATP production in hypertrophied hearts. Am. J. Physiol. 1994, 267, H742-H750. [CrossRef]

80. Mori, J.; Basu, R.; McLean, B.A.; Das, S.K.; Zhang, L.; Patel, V.B.; Wagg, C.S.; Kassiri, Z.; Lopaschuk, G.D.; Oudit, G.Y. Agonist-induced hypertrophy and diastolic dysfunction are associated with selective reduction in glucose oxidation: A metabolic contribution to heart failure with normal ejection fraction. Circ. Heart Fail. 2012, 5, 493-503. [CrossRef]

81. Zhabyeyev, P.; Gandhi, M.; Mori, J.; Basu, R.; Kassiri, Z.; Clanachan, A.; Lopaschuk, G.D.; Oudit, G.Y. Pressure-overload-induced heart failure induces a selective reduction in glucose oxidation at physiological afterload. Cardiovasc. Res. 2013, 97, 676-685. [CrossRef]

82. Hue, L.; Taegtmeyer, H. The Randle cycle revisited: A new head for an old hat. Am. J. Physiol. Endocrinol. Metab. 2009, 297, E578-E591. [CrossRef]

83. Zimmer, H.G.; Ibel, H.; Steinkopff, G. Studies on the hexose monophosphate shunt in the myocardium during development of hypertrophy. Adv. Myocardiol. 1980, 1, 487-492.

84. Gupte, S.A.; Levine, R.J.; Gupte, R.S.; Young, M.E.; Lionetti, V.; Labinskyy, V.; Floyd, B.C.; Ojaimi, C.; Bellomo, M.; Wolin, M.S.; et al. Glucose-6-phosphate dehydrogenase-derived NADPH fuels superoxide production in the failing heart. J. Mol. Cell Cardiol. 2006, 41, 340-349. [CrossRef]

85. Han, Y.M.; Ramprasath, T.; Zou, M.H. beta-hydroxybutyrate and its metabolic effects on age-associated pathology. Exp. Mol. Med. 2020, 52, 548-555. [CrossRef]

86. Murray, A.J.; Knight, N.S.; Cole, M.A.; Cochlin, L.E.; Carter, E.; Tchabanenko, K.; Pichulik, T.; Gulston, M.K.; Atherton, H.J.; Schroeder, M.A.; et al. Novel ketone diet enhances physical and cognitive performance. FASEB J. 2016, 30, 4021-4032. [CrossRef]

87. Newman, J.C.; Covarrubias, A.J.; Zhao, M.; Yu, X.; Gut, P.; Ng, C.P.; Huang, Y.; Haldar, S.; Verdin, E. Ketogenic Diet Reduces Midlife Mortality and Improves Memory in Aging Mice. Cell Metab. 2017, 26, 547-557. [CrossRef]

88. Sedej, S. Ketone bodies to the rescue for an aging heart? Cardiovasc. Res. 2018, 114, e1-e2. [CrossRef]

89. Bedi, K.C., Jr.; Snyder, N.W.; Brandimarto, J.; Aziz, M.; Mesaros, C.; Worth, A.J.; Wang, L.L.; Javaheri, A.; Blair, I.A.; Margulies, K.B.; et al. Evidence for Intramyocardial Disruption of Lipid Metabolism and Increased Myocardial Ketone Utilization in Advanced Human Heart Failure. Circulation 2016, 133, 706-716. [CrossRef]

90. Aubert, G.; Martin, O.J.; Horton, J.L.; Lai, L.; Vega, R.B.; Leone, T.C.; Koves, T.; Gardell, S.J.; Kruger, M.; Hoppel, C.L.; et al. The Failing Heart Relies on Ketone Bodies as a Fuel. Circulation 2016, 133, 698-705. [CrossRef]

91. Mudaliar, S.; Alloju, S.; Henry, R.R. Can a Shift in Fuel Energetics Explain the Beneficial Cardiorenal Outcomes in the EMPA-REG OUTCOME Study? A Unifying Hypothesis. Diabetes Care 2016, 39, 1115-1122. [CrossRef] [PubMed]

92. Uchihashi, M.; Hoshino, A.; Okawa, Y.; Ariyoshi, M.; Kaimoto, S.; Tateishi, S.; Ono, K.; Yamanaka, R.; Hato, D.; Fushimura, Y.; et al. Cardiac-Specific Bdh1 Overexpression Ameliorates Oxidative Stress and Cardiac Remodeling in Pressure Overload-Induced Heart Failure. Circ. Heart Fail. 2017, 10. [CrossRef] [PubMed]

93. Kates, A.M.; Herrero, P.; Dence, C.; Soto, P.; Srinivasan, M.; Delano, D.G.; Ehsani, A.; Gropler, R.J. Impact of aging on substrate metabolism by the human heart. J. Am. Coll. Cardiol. 2003, 41, 293-299. [CrossRef] 
94. Ledee, D.; Portman, M.A.; Kajimoto, M.; Isern, N.; Olson, A.K. Thyroid hormone reverses aging-induced myocardial fatty acid oxidation defects and improves the response to acutely increased afterload. PLOS ONE 2013, 8, e65532. [CrossRef]

95. Son, N.H.; Ananthakrishnan, R.; Yu, S.; Khan, R.S.; Jiang, H.; Ji, R.; Akashi, H.; Li, Q.; O’Shea, K.; Homma, S.; et al. Cardiomyocyte aldose reductase causes heart failure and impairs recovery from ischemia. PLOS ONE 2012, 7, e46549. [CrossRef]

96. Campbell, F.M.; Kozak, R.; Wagner, A.; Altarejos, J.Y.; Dyck, J.R.; Belke, D.D.; Severson, D.L.; Kelly, D.P.; Lopaschuk, G.D. A role for peroxisome proliferator-activated receptor alpha (PPARalpha) in the control of cardiac malonyl-CoA levels: Reduced fatty acid oxidation rates and increased glucose oxidation rates in the hearts of mice lacking PPARalpha are associated with higher concentrations of malonyl-CoA and reduced expression of malonyl-CoA decarboxylase. J. Biol. Chem. 2002, 277, 4098-4103. [CrossRef]

97. Djouadi, F.; Weinheimer, C.J.; Saffitz, J.E.; Pitchford, C.; Bastin, J.; Gonzalez, F.J.; Kelly, D.P. A gender-related defect in lipid metabolism and glucose homeostasis in peroxisome proliferator- activated receptor alphadeficient mice. J. Clin. Investig. 1998, 102, 1083-1091. [CrossRef]

98. Iemitsu, M.; Miyauchi, T.; Maeda, S.; Tanabe, T.; Takanashi, M.; Irukayama-Tomobe, Y.; Sakai, S.; Ohmori, H.; Matsuda, M.; Yamaguchi, I. Aging-induced decrease in the PPAR-alpha level in hearts is improved by exercise training. Am. J. Physiol. Heart Circ. Physiol. 2002, 283, H1750-H1760. [CrossRef]

99. Zhao, L.; Zou, X.; Feng, Z.; Luo, C.; Liu, J.; Li, H.; Chang, L.; Wang, H.; Li, Y.; Long, J.; et al. Evidence for association of mitochondrial metabolism alteration with lipid accumulation in aging rats. Exp. Gerontol. 2014, 56, 3-12. [CrossRef]

100. Van der Meer, R.W.; Rijzewijk, L.J.; Diamant, M.; Hammer, S.; Schar, M.; Bax, J.J.; Smit, J.W.; Romijn, J.A.; de Roos, A.; Lamb, H.J. The ageing male heart: Myocardial triglyceride content as independent predictor of diastolic function. Eur. Heart J. 2008, 29, 1516-1522. [CrossRef]

101. Thiagarajan, D.; Ananthakrishnan, R.; Zhang, J.; O'Shea, K.M.; Quadri, N.; Li, Q.; Sas, K.; Jing, X.; Rosario, R.; Pennathur, S.; et al. Aldose Reductase Acts as a Selective Derepressor of PPARgamma and the Retinoic Acid Receptor. Cell Rep. 2016, 15, 181-196. [CrossRef] [PubMed]

102. Krishnan, J.; Suter, M.; Windak, R.; Krebs, T.; Felley, A.; Montessuit, C.; Tokarska-Schlattner, M.; Aasum, E.; Bogdanova, A.; Perriard, E.; et al. Activation of a HIF1alpha-PPARgamma axis underlies the integration of glycolytic and lipid anabolic pathways in pathologic cardiac hypertrophy. Cell Metab. 2009, 9, 512-524. [CrossRef] [PubMed]

103. Bertero, E.; Maack, C. Metabolic remodelling in heart failure. Nat. Rev. Cardiol. 2018, 15, 457-470. [CrossRef] [PubMed]

104. Doenst, T.; Nguyen, T.D.; Abel, E.D. Cardiac metabolism in heart failure: Implications beyond ATP production. Circ Res 2013, 113, 709-724. [CrossRef]

105. Slawik, M.; Vidal-Puig, A.J. Lipotoxicity, overnutrition and energy metabolism in aging. Ageing Res. Rev. 2006, 5, 144-164. [CrossRef]

106. Koonen, D.P.; Febbraio, M.; Bonnet, S.; Nagendran, J.; Young, M.E.; Michelakis, E.D.; Dyck, J.R. CD36 expression contributes to age-induced cardiomyopathy in mice. Circulation 2007, 116, 2139-2147. [CrossRef]

107. Borradaile, N.M.; Schaffer, J.E. Lipotoxicity in the heart. Curr. Hypertens. Rep. 2005, 7, 412-417. [CrossRef]

108. Drosatos, K.; Schulze, P.C. Cardiac lipotoxicity: Molecular pathways and therapeutic implications. Curr. Heart Fail. Rep. 2013, 10, 109-121. [CrossRef]

109. Gomez, L.A.; Monette, J.S.; Chavez, J.D.; Maier, C.S.; Hagen, T.M. Supercomplexes of the mitochondrial electron transport chain decline in the aging rat heart. Arch. Biochem. Biophys. 2009, 490, 30-35. [CrossRef]

110. Kwong, L.K.; Sohal, R.S. Age-related changes in activities of mitochondrial electron transport complexes in various tissues of the mouse. Arch. Biochem. Biophys. 2000, 373, 16-22. [CrossRef]

111. Lesnefsky, E.J.; Gudz, T.I.; Moghaddas, S.; Migita, C.T.; Ikeda-Saito, M.; Turkaly, P.J.; Hoppel, C.L. Aging decreases electron transport complex III activity in heart interfibrillar mitochondria by alteration of the cytochrome c binding site. J. Mol. Cell Cardiol. 2001, 33, 37-47. [CrossRef] [PubMed]

112. Partridge, L.; Fuentealba, M.; Kennedy, B.K. The quest to slow ageing through drug discovery. Nat. Rev. Drug Discov. 2020, 19, 513-532. [CrossRef]

113. Moskalev, A.; Chernyagina, E.; Tsvetkov, V.; Fedintsev, A.; Shaposhnikov, M.; Krut'ko, V.; Zhavoronkov, A.; Kennedy, B.K. Developing criteria for evaluation of geroprotectors as a key stage toward translation to the clinic. Aging Cell 2016, 15, 407-415. [CrossRef] [PubMed] 
114. Bellantuono, I. Find drugs that delay many diseases of old age. Nature 2018, 554, 293-295. [CrossRef] [PubMed]

115. Yousefzadeh, M.J.; Zhu, Y.; McGowan, S.J.; Angelini, L.; Fuhrmann-Stroissnigg, H.; Xu, M.; Ling, Y.Y.; Melos, K.I.; Pirtskhalava, T.; Inman, C.L.; et al. Fisetin is a senotherapeutic that extends health and lifespan. EBioMedicine 2018, 36, 18-28. [CrossRef] [PubMed]

116. Xu, M.; Pirtskhalava, T.; Farr, J.N.; Weigand, B.M.; Palmer, A.K.; Weivoda, M.M.; Inman, C.L.; Ogrodnik, M.B.; Hachfeld, C.M.; Fraser, D.G.; et al. Senolytics improve physical function and increase lifespan in old age. Nat. Med. 2018, 24, 1246-1256. [CrossRef]

117. Mitchell, S.J.; Bernier, M.; Aon, M.A.; Cortassa, S.; Kim, E.Y.; Fang, E.F.; Palacios, H.H.; Ali, A.; Navas-Enamorado, I.; Di Francesco, A.; et al. Nicotinamide Improves Aspects of Healthspan, but Not Lifespan, in Mice. Cell Metab. 2018, 27, 667-676. [CrossRef]

118. Childs, B.G.; Baker, D.J.; Wijshake, T.; Conover, C.A.; Campisi, J.; van Deursen, J.M. Senescent intimal foam cells are deleterious at all stages of atherosclerosis. Science 2016, 354, 472-477. [CrossRef]

119. Kraig, E.; Linehan, L.A.; Liang, H.; Romo, T.Q.; Liu, Q.; Wu, Y.; Benavides, A.D.; Curiel, T.J.; Javors, M.A.; Musi, N.; et al. A randomized control trial to establish the feasibility and safety of rapamycin treatment in an older human cohort: Immunological, physical performance, and cognitive effects. Exp. Gerontol. 2018, 105, 53-69. [CrossRef]

120. Campbell, J.M.; Bellman, S.M.; Stephenson, M.D.; Lisy, K. Metformin reduces all-cause mortality and diseases of ageing independent of its effect on diabetes control: A systematic review and meta-analysis. Ageing Res. Rev. 2017, 40, 31-44. [CrossRef]

121. Strong, R.; Miller, R.A.; Antebi, A.; Astle, C.M.; Bogue, M.; Denzel, M.S.; Fernandez, E.; Flurkey, K.; Hamilton, K.L.; Lamming, D.W.; et al. Longer lifespan in male mice treated with a weakly estrogenic agonist, an antioxidant, an alpha-glucosidase inhibitor or a Nrf2-inducer. Aging Cell 2016, 15, 872-884. [CrossRef] [PubMed]

122. Miller, R.A.; Harrison, D.E.; Astle, C.M.; Bogue, M.A.; Brind, J.; Fernandez, E.; Flurkey, K.; Javors, M.; Ladiges, W.; Leeuwenburgh, C.; et al. Glycine supplementation extends lifespan of male and female mice. Aging Cell 2019, 18, e12953. [CrossRef] [PubMed]

123. Harrison, D.E.; Strong, R.; Sharp, Z.D.; Nelson, J.F.; Astle, C.M.; Flurkey, K.; Nadon, N.L.; Wilkinson, J.E.; Frenkel, K.; Carter, C.S.; et al. Rapamycin fed late in life extends lifespan in genetically heterogeneous mice. Nature 2009, 460, 392-395. [CrossRef] [PubMed]

124. Strong, R.; Miller, R.A.; Astle, C.M.; Floyd, R.A.; Flurkey, K.; Hensley, K.L.; Javors, M.A.; Leeuwenburgh, C.; Nelson, J.F.; Ongini, E.; et al. Nordihydroguaiaretic acid and aspirin increase lifespan of genetically heterogeneous male mice. Aging Cell 2008, 7, 641-650. [CrossRef] [PubMed]

Publisher's Note: MDPI stays neutral with regard to jurisdictional claims in published maps and institutional affiliations.

(C) 2020 by the authors. Licensee MDPI, Basel, Switzerland. This article is an open access article distributed under the terms and conditions of the Creative Commons Attribution (CC BY) license (http://creativecommons.org/licenses/by/4.0/). 